\title{
Oxidation as an early stage in the multistep thermal decomposition of uranium(IV) oxalate into $\mathrm{U}_{3} \mathrm{O}_{8}$
}

Lénaïc DESFOUGERES ${ }^{1,2,3}$, Éléonore WELCOMME ${ }^{1}$, Maelig OLLIVIER ${ }^{2}$, Philippe M. MARTIN ${ }^{1}$,

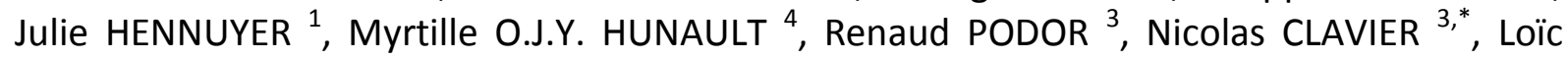
FAVERGEON ${ }^{2}$

${ }^{1}$ CEA, DES, ISEC, DMRC, Univ Montpellier, Marcoule, France

${ }^{2}$ Mines Saint-Etienne, Univ Lyon, CNRS, UMR 5307 LGF, Centre SPIN, F - 42023 Saint-Etienne, France

${ }^{3}$ ICSM, Univ Montpellier, CEA, CNRS, ENSCM, Bagnols-sur-Cèze, France

${ }^{4}$ Synchrotron SOLEIL, L'Orme des Merisiers, Saint Aubin BP 48, 91192 Gif-sur-Yvette, France

*Corresponding author : Nicolas Clavier, nicolas.clavier@icsm.fr

\begin{abstract}
The thermal decomposition of actinides oxalates greatly depends on the oxidation state of the cation, the gas involved and the physical characteristics of the precursor. In the actinides series, uranium(IV) oxalate $\mathrm{U}\left(\mathrm{C}_{2} \mathrm{O}_{4}\right)_{2} \cdot 6 \mathrm{H}_{2} \mathrm{O}$ can be viewed as a peculiar case, as its sensibility towards oxidation leads to a specific series of reactions when heating under oxygen atmosphere. In order to clarify the disagreements existing in the literature, particularly concerning potential carbonate intermediates and the possible transitory existence of $\mathrm{UO}_{3}$, we show here an extended characterization of the different intermediates through a combination of X-Ray diffraction, vibrational spectroscopies and X-Ray absorption near edge spectroscopy.

In this frame, uranium oxidation was found to occur at low temperature $\left(200^{\circ} \mathrm{C}\right)$ concomitantly to the onset of oxalate groups decomposition, leading to an amorphous oxo-oxalato compound. Pursuing the thermal conversion up to $350^{\circ} \mathrm{C}$ led to complete oxidation of $\mathrm{U}(\mathrm{IV})$ into $\mathrm{U}(\mathrm{VI})$, then to the formation of amorphous $\mathrm{UO}_{3}$ still bearing adsorbed carbonates. The first pure oxide formed during the thermal conversion was further identified to sub-stoichiometric $\mathrm{UO}_{3-\delta}$ after heating at $550^{\circ} \mathrm{C}$. Finally, $\mathrm{U}_{3} \mathrm{O}_{8}$ was obtained as the final stable phase after heating above $660^{\circ} \mathrm{C}$. The mechanism of thermal conversion of uranium(IV) oxalate into oxide under oxygen is then driven by a complex interplay between redox reactions and decomposition of the organic fractions. Such chemical reactions were also found to significantly modify the morphology of the powder through HT-ESEM observations : decomposition led the size of the aggregates to reduce by $20 \%$ while uranium oxidation clearly promoted growth within the agglomerates.
\end{abstract}




\section{INTRODUCTION}

The synthesis of oxides through the precipitation of a metal ion by oxalic acid, followed by the calcination of the insoluble salt produced, is a method widely used in catalysis, electrolyte materials fabrication, etc... ${ }^{1-4}$. One of the main advantage of this process is the possibility to gain fine control of the physical characteristics of the final oxide through the optimization of the precipitation and thermal treatment conditions. Moreover, the limited number of steps involved leads to an easy implementation at the industrial scale. This method then finds its place in the field of the nuclear fuel cycle, especially during spent fuel recycling. As such, plutonium(IV) is currently precipitated as $\mathrm{Pu}\left(\mathrm{C}_{2} \mathrm{O}_{4}\right)_{2} \cdot 6 \mathrm{H}_{2} \mathrm{O}$ in the back-end of the French PUREX partitioning process, then calcined into $\mathrm{PuO}_{2}$ to further refabricate fresh $(\mathrm{U}, \mathrm{Pu}) \mathrm{O}_{2} \mathrm{MOx}$ fuels ${ }^{5}$. Oxalic route is also envisaged in order to operate the co-precipitation of uranium, plutonium and/or minor actinides, with the aim to prepare advanced fuels for fast-neutron reactors ${ }^{6,7}$. Finally, it is also involved in the reprocessing scheme of composite $\left(\mathrm{Th}_{1}{ }^{233} \mathrm{U}\right) \mathrm{O}_{2}-(\mathrm{Th}, \mathrm{Pu}) \mathrm{O}_{2}$ fuels planned to be used in advanced heavy water reactors (AHWR) ${ }^{8,9}$. In all these examples, the selectivity of the oxalic precipitation for some actinides, according to the conditions of precipitation, enables an additional level of control on the nature of the metal cation present in the oxide ${ }^{10,11}$.

Thermal decomposition of metal oxalates was studied for decades, leading to several reactive pathways proposed in the literature ${ }^{12-16}$. Nevertheless, none of these mechanisms could properly summarize the numerous specificities observed, such as the presence of different carbonates and oxo-carbonates intermediates, or the finely divided state of a metal at the end of the reaction leading to pyrophoric effect ${ }^{17}$. To explain such a complex behavior, a recent publication ${ }^{18}$ pointed out that the decomposition of $\mathrm{C}_{2} \mathrm{O}_{4}$ groups consists of a multitude of concurrent and cascading reactions, involving both heterogeneous (solid/gas) and homogeneous (gas/gas and solid/solid) reactions. As such, three parameters can significantly impact the physico-chemical transformations occurring throughout the thermal treatment ${ }^{13}$ : the nature, and more specifically, the oxidation state of the metal cation, the calcination atmosphere, and the physical characteristics of the powder (especially its granulometry and its porosity). These parameters are notably important in the case of the thermal decomposition of uranium(IV) oxalate $\mathrm{U}\left(\mathrm{C}_{2} \mathrm{O}_{4}\right)_{2} \cdot 6 \mathrm{H}_{2} \mathrm{O}$, for which heat treatment under oxidizing conditions leads to series of reactions with specific intermediates and a heavily exothermic behavior ${ }^{19}$.

In this context, if the scientific community mostly agree on the thermal decomposition mechanism of uranyl oxalates ${ }^{20,21}$, a wide range of reaction intermediates is still proposed from one study to another ${ }^{19,}$ 22-26 when addressing the decomposition stages of uranium(IV) oxalate (Figure 1). First, some of those studies identified different compounds for the same reaction pathway. This is particularly the case during the decomposition of oxalate fractions, which yields carbonate, oxocarbonate, or even oxide compounds, depending on the authors. Additionally, even when identical intermediates were evidenced, significant discrepancies in reaction temperatures are noticed. As a matter of example, $\mathrm{UO}_{3}$ is reported to form between $310^{\circ} \mathrm{C}$ and more than $370^{\circ} \mathrm{C} 24,27$.

Despite this situation, two common agreements may be drawn up. First, the final product of the calcination is either $\mathrm{U}_{3} \mathrm{O}_{8}$ in air or pure $\mathrm{O}_{2}$ atmosphere, or $\mathrm{UO}_{2}$ otherwise. Secondly, the dehydration seems to occur in three steps, such as : 


$$
\begin{aligned}
& \mathrm{U}\left(\mathrm{C}_{2} \mathrm{O}_{4}\right)_{2} \cdot 6 \mathrm{H}_{2} \mathrm{O} \rightarrow \mathrm{U}\left(\mathrm{C}_{2} \mathrm{O}_{4}\right)_{2} \cdot 2 \mathrm{H}_{2} \mathrm{O}+4 \mathrm{H}_{2} \mathrm{O} \\
& \mathrm{U}\left(\mathrm{C}_{2} \mathrm{O}_{4}\right)_{2} \cdot 2 \mathrm{H}_{2} \mathrm{O} \rightarrow \mathrm{U}\left(\mathrm{C}_{2} \mathrm{O}_{4}\right)_{2} \cdot \mathrm{H}_{2} \mathrm{O}+\mathrm{H}_{2} \mathrm{O} \\
& \mathrm{U}\left(\mathrm{C}_{2} \mathrm{O}_{4}\right)_{2} \cdot \mathrm{H}_{2} \mathrm{O} \rightarrow \mathrm{U}\left(\mathrm{C}_{2} \mathrm{O}_{4}\right)_{2}+\mathrm{H}_{2} \mathrm{O}
\end{aligned}
$$

In this frame, it is important to note that $\mathrm{U}\left(\mathrm{C}_{2} \mathrm{O}_{4}\right)_{2} \cdot 6 \mathrm{H}_{2} \mathrm{O}$ is frequently reported to age at low temperature or under vacuum, leading to the partial formation of the $\mathrm{U}\left(\mathrm{C}_{2} \mathrm{O}_{4}\right)_{2} \cdot 2 \mathrm{H}_{2} \mathrm{O}$ dihydrate form 22.

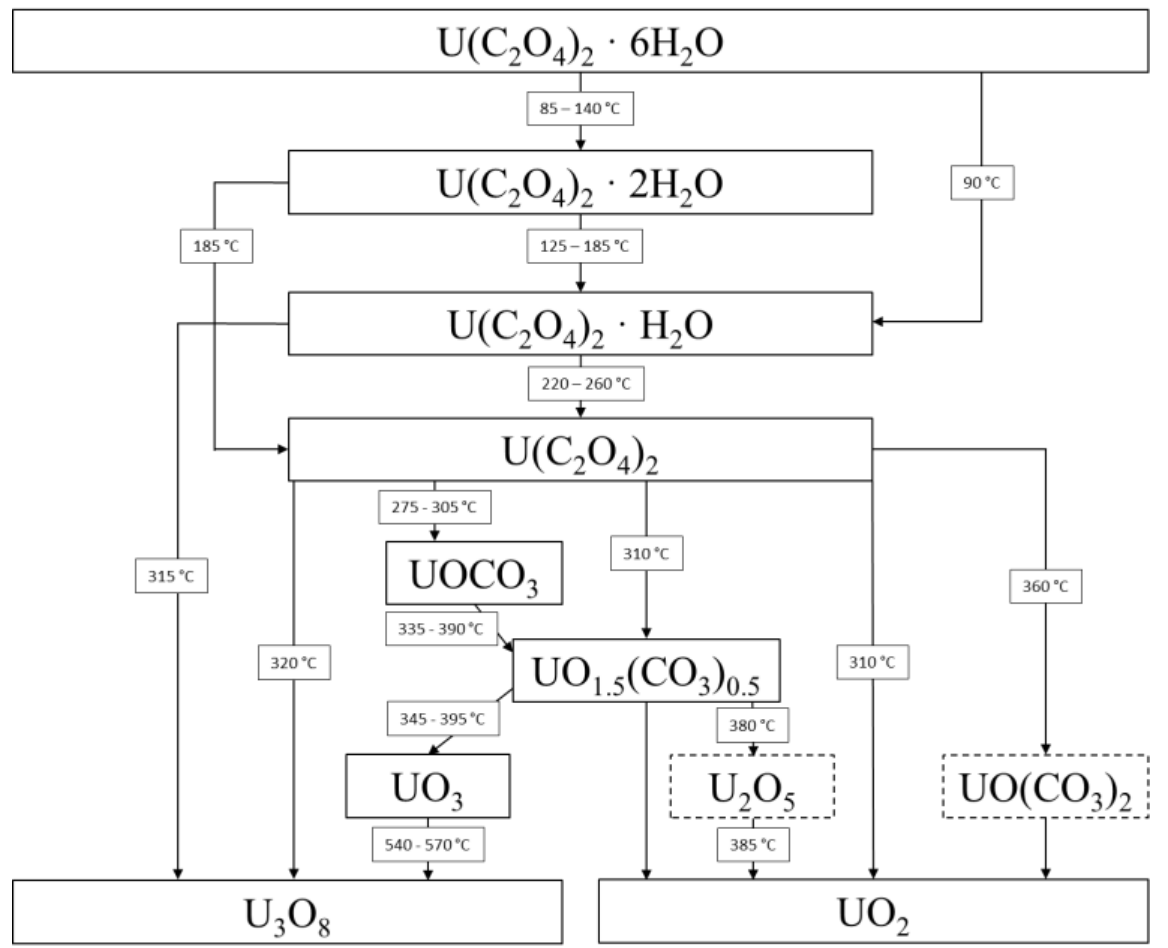

Figure 1. Global representation of published divergent reactive pathways ${ }^{19,22-26}$ describing decomposition stages of uranium(IV) oxalate. The dotted boxes point intermediates existing only under inert atmosphere.

This consensus still leave a gap open as the most important part of the mass loss, i.e. between the anhydrous uranium(IV) oxalate and the final product, is not tackled. Under air or pure $\mathrm{O}_{2}$ atmosphere, main disagreements deal about potential carbonate intermediates, and the possible transitory existence of $\mathrm{UO}_{3}$. In turn, the potential formation of $\mathrm{UO}_{3}$ leads to a question on the uranium oxidation process within the general reaction pathway, as all the carbonate intermediates proposed in the literature are tetravalent uranium species. Two competing hypotheses can be drawn: the first one argues for a direct oxidation of uranium(IV) into uranium(V-VI) (formation of $\mathrm{U}_{3} \mathrm{O}_{8}$ ) while the other accounts for the oxidation of uranium(IV) into uranium(VI) at high temperature (formation of $\mathrm{UO}_{3}$ ) followed by a reduction as uranium (V-VI).

The discrepancies among the different studies reported in the literature are mainly caused by three different elements. First, a lack of information on the precursors used (particularly regarding their initial hydration state and specific surface area) hinders any direct and reliable comparison between the studies ${ }^{24}$. Secondly, the exact conditions of calcination are not always specified, especially in terms of masses or atmosphere (gas type and pressure) used ${ }^{28}$. Thirdly and even more importantly, 
the exclusive use of mass measurements (i.e. thermogravimetric experiments) to conclude on the nature of a supposed intermediate leaves room for doubt and hypotheses.

In this framework, this study aims to reinvestigate the decomposition of uranium(IV) oxalate hexahydrate $\mathrm{U}\left(\mathrm{C}_{2} \mathrm{O}_{4}\right)_{2} \cdot 6 \mathrm{H}_{2} \mathrm{O}$ under oxidizing atmosphere $\left(\mathrm{He} / \mathrm{O}_{2}\right.$ mixture with $25 / 75$ volume ratio). For that purpose, differential scanning calorimetry (DSC) and thermogravimetric analyses (TG) were first used in order to monitor the thermal behavior of uranium oxalate. They allowed to point out and isolate the different reaction intermediates. A large set of solid characterization techniques ( $X$ Ray diffraction, vibrational spectroscopies and X-Ray absorption near edge spectroscopy) was then used to unambiguously identify these compounds. Finally, in situ High-Temperature Environmental Scanning Electron Microscopy observations were performed to evaluate the impact of the different chemical transformations on the microstructural characteristics of the powder.

\section{EXPERIMENTAL SECTION}

\section{II.1 Uranium oxalate hexahydrate synthesis}

$35 \mathrm{~g}$ of uranium(IV) oxalate hexahydrate $\mathrm{U}\left(\mathrm{C}_{2} \mathrm{O}_{4}\right)_{2} \cdot 6 \mathrm{H}_{2} \mathrm{O}$ were synthesized through continuous precipitation in a stirred reactor, following the protocol initially reported by Bertrand-Andrieu et al. ${ }^{29}$. Conventional chemicals used were supplied by VWR and were of analytical grade, while uranium originates from Orano (Bessines/Gartempe, France). Two solutions, one containing uranium(IV) in nitric acid media $\left(C_{U}=35.7 \mathrm{~g} . \mathrm{L}^{-1}\right)$ with hydrazine (in order to prevent any oxidation of $\mathrm{U}(\mathrm{IV}$ ) into $\mathrm{U}(\mathrm{VI}))$, and the other oxalic acid, were added dropwise at the same speed $\left(10 \mathrm{~mL} \cdot \mathrm{min}^{-1}\right)$ to a mixture of oxalic acid and hydrazine in the stirring reactor. At equilibrium, molar concentration of hydrazine was $0.025 \mathrm{M}$ and molar concentration of nitric acid was $2 \mathrm{M}$. Also, a $300 \%$ excess in oxalic acid regarding uranium(IV) was considered, in order to ensure a quantitative precipitation of the cations. The precipitate was washed with a $20 \mathrm{~mL}$ mixture of deionized water and ethanol (50/50 \% ${ }_{\text {vol. }}$ ), filtered, then left to dry one day at room temperature. The dry powder was analyzed by X-Ray diffraction and vibrational spectroscopies before monitoring its thermal conversion using thermogravimetric analyses.

\section{II.2 Characterization techniques}

ESEM observations. Before their observation, the samples were systematically deposited on carbon adhesive tape without any additional preparation. A FEI Quanta 200 Environmental Scanning Electron Microscope (ESEM), equipped with an Everhart-Thornley Detector (ETD) and a BackScattered Electron Detector (BSED) was used to record images with an acceleration voltage of 30kV under high vacuum conditions.

The decomposition of uranium(IV) oxalate was also monitored in situ using a specific high temperature stage attached to the ESEM. The sample was heated from RT to $1000^{\circ} \mathrm{C}$ with a $10^{\circ} \mathrm{C} \cdot \mathrm{min}^{-}$

${ }^{1}$ heating rate, while continuously recording high magnification images on selected grains. The air pressure in the ESEM chamber was kept to 200Pa during the experiment. Image processing to extract the grain surface was performed using the Fiji software ${ }^{30}$. 
PXRD. Powder X-Ray Diffraction (PXRD) diagrams were collected using a Bruker D8 diffractometer

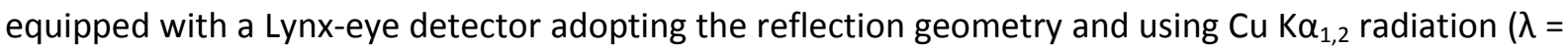
$1.54184 \AA$ A). PXRD patterns were recorded at room temperature in the $5-80^{\circ}$ range $(2 \theta)$, a step size of $\Delta(2 \theta)=0.02^{\circ}$ and a total counting time of about 3 hours per sample.

Vibrational spectroscopies. Raman spectra were recorded using a Horiba - Jobin Yvon Aramis apparatus equipped with an edge filter and using a Nd:YAG laser $(532 \mathrm{~nm})$. In order to avoid any laser-induced degradation of the compound, the power was lowered to about $0.5 \mathrm{~mW}$ depending on the sample analyzed. The laser beam was then focused on a small fraction of powder deposited on a glass lamella using an Olympus BX 41 microscope. A $\times 100$ objective with a numerical aperture of 0.9 , resulting in a spot size of about $1 \mu \mathrm{m}^{2}$ was used. The scattered Raman light was collected in a $180^{\circ}$ backscattering geometry and dispersed by a grating of 1800 grooves $/ \mathrm{mm}$ after having passed a 150 $\mu \mathrm{m}$ entrance slit, resulting in a spectral resolution lower than $1 \mathrm{~cm}^{-1}$. For each spectrum, a dwell time of 10 seconds was considered with an average of 15 scans. Before analysis, the apparatus was calibrated with a silicon wafer, using the first-order Si line at $520.7 \mathrm{~cm}^{-1}$.

Fourier-Transform Infrared (FTIR) spectra were recorded in the $400-4000 \mathrm{~cm}^{-1}$ range using a MIR TF Vertex 70 device. Powdered samples were deposited at the surface of an Attenuated Total Reflectance (ATR) crystal. The spectra collected in such operating conditions exhibited a resolution lower than $4 \mathrm{~cm}^{-1}$.

Chemical Analysis. The amount of residual carbon in the samples prepared was determined using a LECO CS230 Carbon/Sulfur analyzer. Typical mass of $20 \mathrm{mg}$ of powder was considered for each analysis. This latter consisted in the complete combustion of the sample under oxygen atmosphere and the subsequent determination of $\mathrm{CO}_{2}$ concentration by IR absorption. In order to recover quantitative values, a blank and a series of standards were first measured. For starting oxalate and reaction intermediates stabilized up to $200^{\circ} \mathrm{C}$, the standards series was in the $5-15 \mathrm{wt} . \% \mathrm{C}$ range, while it was $0-1$ wt.\% C for compounds obtained above. All the samples were analyzed twice to ensure the repeatability of the measurement.

Thermogravimetric analyses. Thermal transformations were monitored using two thermogravimetric devices. For the Thermogravimetry Analysis (TGA) study as well as isobaric and isothermal experiments, a high performance symmetrical thermobalance (Setaram TAG 16) was used. Between 30 and $40 \mathrm{mg}$ of powder were placed in an alumina crucible with a diameter of $0.8 \mathrm{~mm}$, resulting in an approximate filling height of less than $1 \mathrm{~mm}$. Vacuum was done in the thermobalance during 30 minutes then dry gas (He or mixture of $\mathrm{He} / \mathrm{O}_{2}(25 / 75)$ ) was introduced up to atmospheric pressure with a constant flow at $4 \mathrm{~L} . \mathrm{h}^{-1}$. For TGA measurements, the sample was first heated to $170^{\circ} \mathrm{C}$ at $\beta=1{ }^{\circ} \mathrm{C} \cdot \mathrm{min}^{-1}$ in order to stabilize the anhydrous form of the oxalate. By this way, it is possible to avoid any bias due to the partial dehydration of $\mathrm{U}\left(\mathrm{C}_{2} \mathrm{O}_{4}\right)_{2} \cdot 6 \mathrm{H}_{2} \mathrm{O}$ into $\mathrm{U}\left(\mathrm{C}_{2} \mathrm{O}_{4}\right)_{2} \cdot 2 \mathrm{H}_{2} \mathrm{O}$ under vacuum (see section III.2.). After stabilizing the measurement conditions by maintaining the sample at $170^{\circ} \mathrm{C}$ for 20 hours, TG-DTG curves were obtained by heating the sample to $1000^{\circ} \mathrm{C}$ at $\beta=$ $1^{\circ} \mathrm{C} \cdot \mathrm{min}^{-1}$. For isothermal measurements, the sample was heated to different programmed temperatures $\left(130 \leq \mathrm{T} \leq 655^{\circ} \mathrm{C}\right)$ at $\beta=1^{\circ} \mathrm{C} \cdot \mathrm{min}^{-1}$ then was held for 24 hours.

For the combination of thermogravimetric and differential scanning calorimetry analyses (TG-DSC), a Sensys Evo thermobalance from Setaram was used. The sample holder was a platinum crucible with a diameter of $0.5 \mathrm{~mm}$ containing $25 \mathrm{mg}$ of powder. The sample was placed in the TG-DSC instrument 


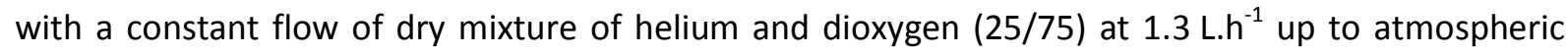
pressure. The sample was then heated up to $800^{\circ} \mathrm{C}$ at $\beta=1^{\circ} \mathrm{C} \cdot \mathrm{min}^{-1}$.

HERFD-XANES. X-ray absorption spectra were measured at the MARS beamline of the SOLEIL synchrotron (Saint-Aubin, France) ${ }^{31}$. The storage ring was operating in top-up mode at an electron current of $500 \mathrm{~mA}, 2.5 \mathrm{GeV}$. The beam size on sample was $250 \mu \mathrm{m} \times 150 \mu \mathrm{m}$ FWHM (HxV). HighEnergy Resolution Fluorescence Detected X-Ray Absorption Near-Edge Spectroscopy (HERFD-XANES) was performed at the $U$ M4-edge $(3.7 \mathrm{keV})$ using a double-crystal monochromator (DCM) and a pair of $\mathrm{Si}(111)$ crystals.. Higher harmonics rejection and vertical focusing was achieved using the Si strip of the mirrors inserted before and after the DCM with a 4 mrad incidence angle. The incident energy was calibrated using the absorption K-edge of potassium in a $\mathrm{KBr}$ pellet $(3.608 \mathrm{keV})$. The incident $\mathrm{X}$ ray flux on the sample position was $1.9 \cdot 10^{9} \mathrm{ph} / \mathrm{s}$ at $3.5 \mathrm{keV}$. The $\mathrm{M} \beta$ emission line of uranium (3.339keV) was analyzed using the 220 reflection of a Si(220) bent stripped crystal analyzer with a curvature radius of $1 \mathrm{~m}$. A He-filled chamber was used to reduce the scattering of the incident and emitted $\mathrm{X}$-rays by the air between the sample and the crystal analyzer and the detector. The overall energy resolution of the emission spectrometer was $1 \mathrm{eV}$ as determined from the FWHM of the elastic scattering peak at the double energy. The HERFD-XANES $\mathrm{M}_{4}$ data were collected with a $1 \mathrm{eV}$ step between 3.710 and $3.722 \mathrm{keV}$, then with a $0.1 \mathrm{eV}$ step in the 3.722-3.733 keV range, then finally with a $1 \mathrm{eV}$ step between 3.733 and $3.770 \mathrm{keV}$. All the spectra were normalized at the maximum of absorption using the ATHENA software ${ }^{32}$. The HERFD-XANES white-line maxima have been taken as the first zero-crossing of the second derivative.

To allow comparisons, $\mathrm{UO}_{2}$ (dense pellet sintered at $1700^{\circ} \mathrm{C}$ in $\mathrm{Ar}-5 \% \mathrm{H}_{2}$ atmosphere) was chosen as pure $\mathrm{U}(\mathrm{IV})$ standard, while a $\mathrm{U}_{4} \mathrm{O}_{9}$ spectrum previously collected at the ESRF-ID26 beamline was used as a mixed standard for $\mathrm{U}(\mathrm{IV}) / \mathrm{U}(\mathrm{V})$ with a $1 / 1$ ratio ${ }^{33}$. This latter sample was obtained by solid-state chemistry from a mixture of $\mathrm{UO}_{2}$ and $\mathrm{U}_{3} \mathrm{O}_{8}$. Its homogeneity and stoichiometry were checked by neutrons diffraction in similar conditions than our experiments (i.e. at room temperature and ambient pressure) ${ }^{34}$. Additionally, a $\mathrm{U}_{3} \mathrm{O}_{8}$ sample obtained by calcination of studtite under air at $800^{\circ} \mathrm{C}$ for 5 hours was taken as a mixed standard for $\mathrm{U}(\mathrm{V}) / \mathrm{U}(\mathrm{VI})$ with a $2 / 1$ ratio ${ }^{33}$ while $\mathrm{UO}_{2}\left(\mathrm{NO}_{3}\right)_{2} \cdot 5 \mathrm{H}_{2} \mathrm{O}$ supplied by Prolabo was selected as pure $\mathrm{U}(\mathrm{VI})$ standard.

\section{RESULTS AND DISCUSSION}

\section{III.1 Initial sample characterization}

The initial precursor obtained after precipitation of uranium(IV) by oxalic acid was first characterized by PXRD (see figure S1 supplied as supporting information). The pattern presents the characteristic diffraction lines of uranium(IV) oxalate hexahydrate with significant reflections at $2 \theta$ values of $11.2^{\circ}$, $13.9^{\circ}, 17.6^{\circ}, 18.1^{\circ}, 22.5^{\circ}, 27.95^{\circ}, 38.1^{\circ}, 42.4^{\circ}$. It is then in good agreement with the structure reported in the literature for $\mathrm{U}\left(\mathrm{C}_{2} \mathrm{O}_{4}\right)_{2} \cdot 6 \mathrm{H}_{2} \mathrm{O}$, which crystallizes in the monoclinic system with $\mathrm{C} 2 / \mathrm{m}$ space group ( $a=9.0953(12) \AA ; b=8.9896(16) \AA ; c=7.9046(13) \AA$ and $\left.\alpha=92.212(10)^{\circ}\right)^{25}$. Also, it is important to note that no supplementary diffraction peaks coming from the monoclinic dihydrate phase ( $\mathrm{C} 2 / \mathrm{c}$ space group) ${ }^{35}$, especially the intense reflection at $14.5^{\circ}$, was observed, indicating that the precursor did not undergo any partial dehydration towards $\mathrm{U}\left(\mathrm{C}_{2} \mathrm{O}_{4}\right)_{2} \cdot 2 \mathrm{H}_{2} \mathrm{O}$ during drying and storage steps. 
FTIR and Raman spectra of the precursor were also collected (Figure 2) and will be used as reference during the characterization of the reaction intermediate. The FTIR spectrum presents the characteristic vibration bands of carboxylate moieties ${ }^{36,37}$, with the strong band located at $1622 \mathrm{~cm}^{-1}$ belonging to the $v_{\text {as }}(\mathrm{CO})$ antisymmetric mode, while the bands at 1489,1352 and the $1310 \mathrm{~cm}^{-1}$ were assigned to the symmetric $\mathrm{v}_{\mathrm{s}}(\mathrm{CO})$ vibration $\left(1352 \mathrm{~cm}^{-1}\right.$ coming as well from the $\mathrm{v}(\mathrm{C}-\mathrm{C})$ vibration). The bands at $793 \mathrm{~cm}^{-1}$ and $474 \mathrm{~cm}^{-1}$ stand for the $\delta(O C O)$ mode (which also contributes to the band at $1310 \mathrm{~cm}^{-1}$ ). Finally, the broad band between 3500 and $2700 \mathrm{~cm}^{-1}$ originates from the symmetric vibration of $\mathrm{OH}$ bonds in water, induced by the hydration state of the compound.

Similarly, the Raman spectrum can be divided into four regions : from 1400 to $1600 \mathrm{~cm}^{-1}$; from 800 to $1100 \mathrm{~cm}^{-1}$; from 400 to $700 \mathrm{~cm}^{-1}$ and from 100 to $400 \mathrm{~cm}^{-1}$. The first three are due to the oxalate groups $^{38}$ : among them, the strong band at $1487 \mathrm{~cm}^{-1}$ comes from the symmetric vibration of $\mathrm{CO}$ bonds, the band at $927 \mathrm{~cm}^{-1}$ originates from the stretching of C-C bonds, and the bands around 529 $\mathrm{cm}^{-1}$ are induced by the $\delta(\mathrm{OCO})$ vibration. The fourth region is characteristic of $\mathrm{U}-\mathrm{O}$ bonds and lattice modes and presents two main bands at 222 and $194 \mathrm{~cm}^{-1}$.
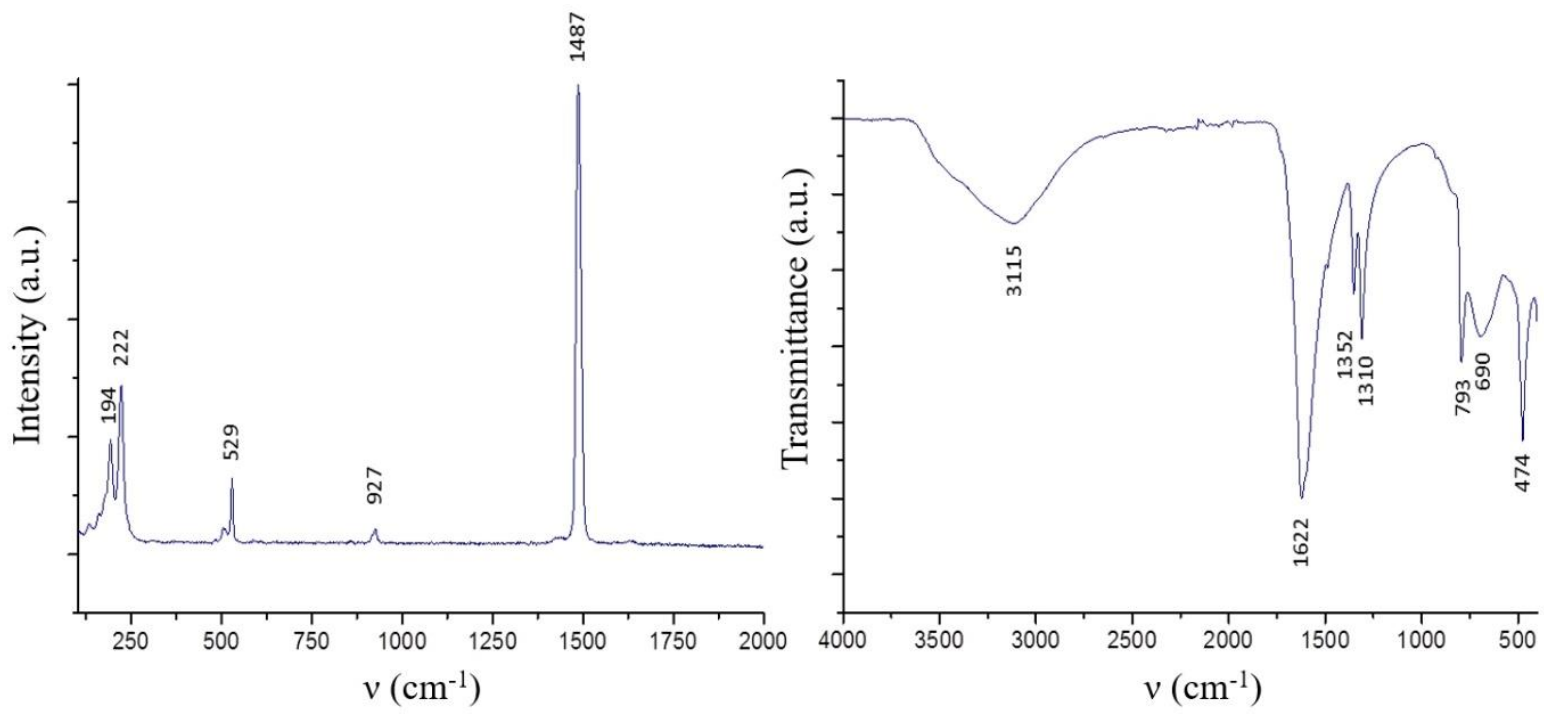

Figure 2. Raman (left) and FT-IR (right) spectra of as-synthesized $U\left(\mathrm{C}_{2} \mathrm{O}_{4}\right)_{2} \cdot 6 \mathrm{H}_{2} \mathrm{O}$.

Finally, the morphology of the precursor powder was checked through ESEM observations (Figure 3). The morphology of actinides and lanthanides oxalates mostly depends on the precipitation conditions and the oxidation state of the metal cation ${ }^{4}$. In this study, uranium(IV) oxalate adopted a square platelet morphology, which is the most common habit reported for this compound ${ }^{39}$. As the particle size is also a key-parameter to compare reaction temperatures from one study to another, the size distribution was controlled thanks to sieve analyses (Granulometric volume distribution, Spraytec, Malvern). Three populations were revealed, the most important around $60 \mu \mathrm{m}$ being assigned to agglomerates. Additionally, isolated particles were typically found in the 6-10 $\mu \mathrm{m}$ range while scarce fine grains of about 1 to $2 \mu \mathrm{m}$ were also detected. 


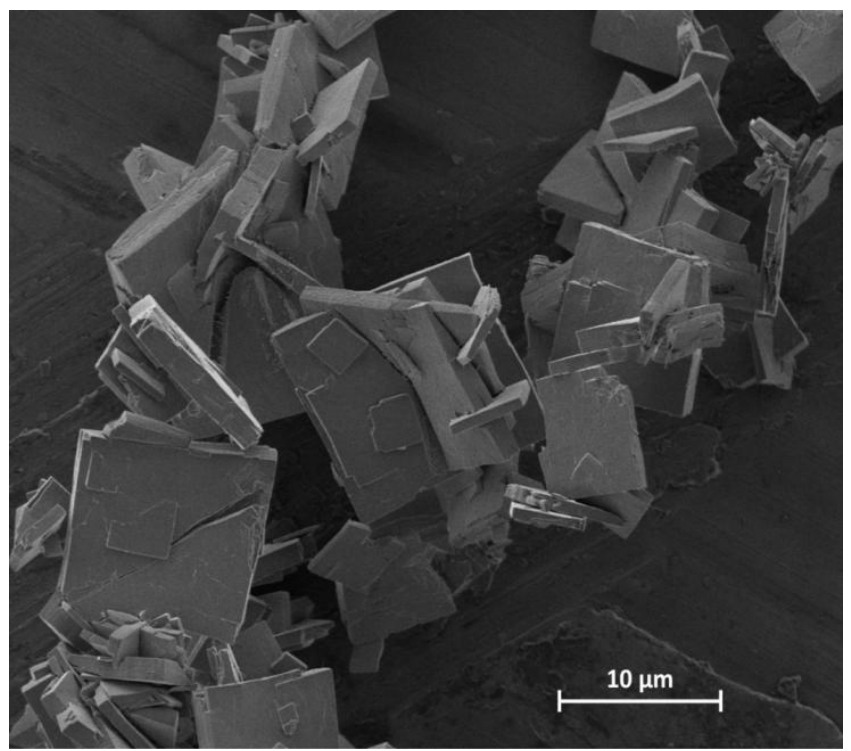

Figure 3. SEM image of $\mathrm{U}\left(\mathrm{C}_{2} \mathrm{O}_{4}\right)_{2} \cdot 6 \mathrm{H}_{2} \mathrm{O}$.

The initial sample characterization then shows that pure $\mathrm{U}\left(\mathrm{C}_{2} \mathrm{O}_{4}\right)_{2} \cdot 6 \mathrm{H}_{2} \mathrm{O}$ was formed during the precipitation process, and that it did not underwent any significant aging. Its molar mass (i.e. $M=522$ g.mol ${ }^{-1}$ ) then will allow accurate calculation of mass changes during TG experiments. Moreover, XRD and spectroscopy data collected at room temperature on the initial precursor will serve as a basis for comparison with reaction intermediates. The morphological information will also be used in a second part of this study, which will address links between the reactions occurring during the heat treatment and the microstructural evolution of the square platelets.

\section{III.2 Thermal decomposition behavior and stabilization of the reaction intermediates}

III.2.1. He atmosphere: Before addressing the thermal behavior of uranium oxalate hexahydrate under oxidizing atmosphere, a first TG analysis was performed under pure helium (99.99\%) in order to establish a reference decomposition path in the absence of any redox reactions (Figure 4). In these conditions, several stages of thermal decomposition led to stoichiometric $\mathrm{UO}_{2}$. This set of decompositions starts with the three dehydration reactions 1, 2 and 3, already described in the introduction (Figure 4b).

However, as the protocol used involving 30 minutes of vacuum before filling the thermobalance with the controlled atmosphere, the first dehydration step partially took place ${ }^{22}$. This explains that the mass measured at the beginning of our experiment did not reach $100 \%$. Applying an isothermal step at $170^{\circ} \mathrm{C}$ then allowed the stabilization of the anhydrous uranium(IV) oxalate in the thermobalance over several hours, as shown in Figure $\mathbf{4 a}$. Indeed, the sample mass did not sustain variations higher than $10 \mu \mathrm{g}$ while the temperature was kept at $170^{\circ} \mathrm{C}$, i.e. 20 hours.

Resuming temperature increase led to the decomposition of the oxalate groups. From the DTG signal (Figure 4c), the rate can be described as a gaussian-shaped curve (that comes from a sigmoidal mass loss), nevertheless with two light contributions towards the end of the transformation. These modifications of the mass loss rate could result from the existence of metastable reaction intermediates for which the thermal decomposition temperatures are the same than that of 
anhydrous uranium oxalate, but whose rates are slightly different ${ }^{40}$. Such differences most likely come from the mechanism of oxalate thermal decomposition, e.g. through the formation of a carbonate compound as a metastable intermediate. They can also result from physical modifications of the platelets, for example through the formation of mesopores, gradually decreasing throughout the thermal process ${ }^{41}$. Nevertheless, the oxalate decomposition could be generally written as follows:

$$
\mathrm{U}\left(\mathrm{C}_{2} \mathrm{O}_{4}\right)_{2} \rightarrow \mathrm{UO}_{2}+2 \mathrm{CO}+2 \mathrm{CO}_{2}
$$
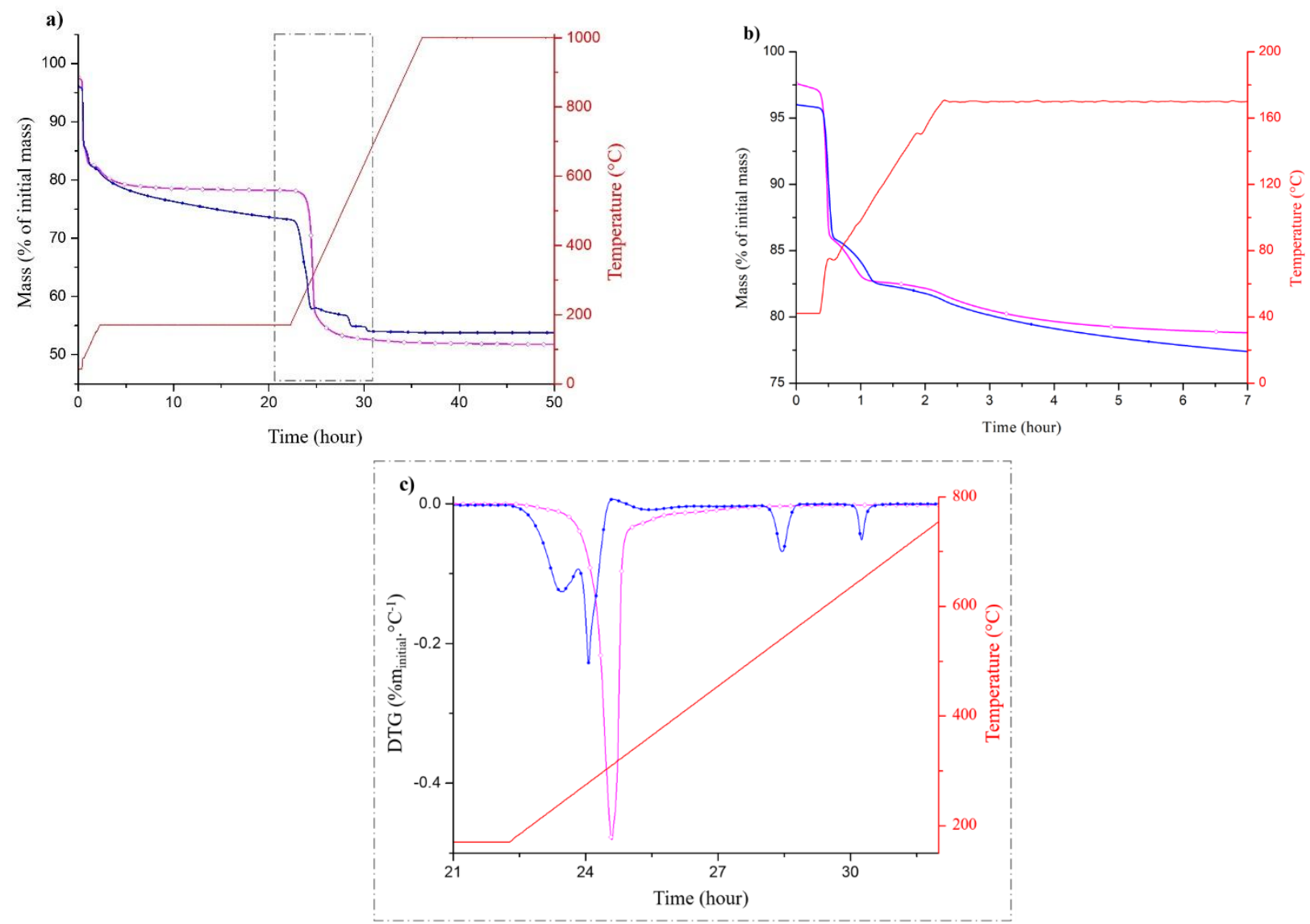

Figure 4. TG analysis (a) of $\mathrm{U}\left(\mathrm{C}_{2} \mathrm{O}_{4}\right)_{2} \cdot 6 \mathrm{H}_{2} \mathrm{O}$ under $\mathrm{He}$ (pink) and under $25 \% \mathrm{He} / 75 \% \mathrm{O}_{2}$ (blue), and temperature (red), with (b) focus on the domain corresponding to dehydration reactions. (c) Associated derivative curves (DTG) between 170 and $750^{\circ} \mathrm{C}$.

III.2.2. Oxidizing atmosphere: When the thermal treatment occurs under a mixture of oxygen and helium ( $75 / 25$ vol.\%, corresponding to $\mathrm{pO}_{2}=76 \mathrm{kPa}$ ), the first two stages of dehydration (occurring before $140^{\circ} \mathrm{C}$ ) are the same than those presented before. However, the sample behavior differs drastically for higher temperatures. At $170^{\circ} \mathrm{C}$, the anhydrous uranium oxalate did not appear to be stable anymore as clearly evidenced in Figure $4 \mathrm{a}$ by the evolution of the mass loss (in blue) during the isotherm dwell, which lead to a lighter intermediate. Given that the onset of the dehydration is identical regardless of the calcination atmosphere, a reaction must occur between the uranium(IV) 
oxalate and oxygen before $170^{\circ} \mathrm{C}$, and by extension, before the temperature of the thermal decomposition of the anhydrous uranium(IV) oxalate.

Above $170^{\circ} \mathrm{C}$, the thermal behavior of the sample is marked by several distinct mass losses. The solid is first stabilized close to $350^{\circ} \mathrm{C}$, during the temperature ramp, before decomposing at $550^{\circ} \mathrm{C}$. The product then stays stable until $655^{\circ} \mathrm{C}$, when it decomposes again into $\mathrm{U}_{3} \mathrm{O}_{8}$ (as confirmed by PXRD), which is the stable uranium oxide under these operating conditions ${ }^{42}$. The use of oxidizing atmosphere during the heat treatment then led to a peculiar behavior starting at $170^{\circ} \mathrm{C}$, and conducting to the stabilization of two reaction intermediates.

The study of the mass loss derivative (DTG) under oxidizing atmosphere also clearly highlighted the behavior described previously (Figure 4c). In this case, the mass loss rate presents a series of maxima directly indicating the existence of multiple reactions. Here, the main mass loss corresponds to three maxima $\left(242^{\circ} \mathrm{C}, 278^{\circ} \mathrm{C}\right.$ and $\left.288^{\circ} \mathrm{C}\right)$, the last two being very close to each other and forming a thin band with a shoulder. At $350^{\circ} \mathrm{C}$, we observed that all these transformations are completed. The last two transformations described previously in Figure 4a then correspond to the two maxima of the mass loss rate, at around 550 and $655^{\circ} \mathrm{C}$.

The maxima observed on the DTG under oxygen-rich atmosphere can be correlated with the thermal behavior thanks to the use of both differential scanning calorimetry and thermogravimetric analysis (Figure 5). The three maxima of the main mass loss are exothermic, and the most important positive heat flow is measured for the last one. The shoulder on the DSC profile corresponds to the thin band on the DTG, while the shoulder on the DTG corresponds to the thin band on the DSC. Therefore, it is likely that the small mass loss (associated with the third transformation) contributes to a large part of the thermal behavior. As a side note, it can be noticed that the dehydration steps observed up to $150^{\circ} \mathrm{C}$, as well as the last reaction, are endothermic.

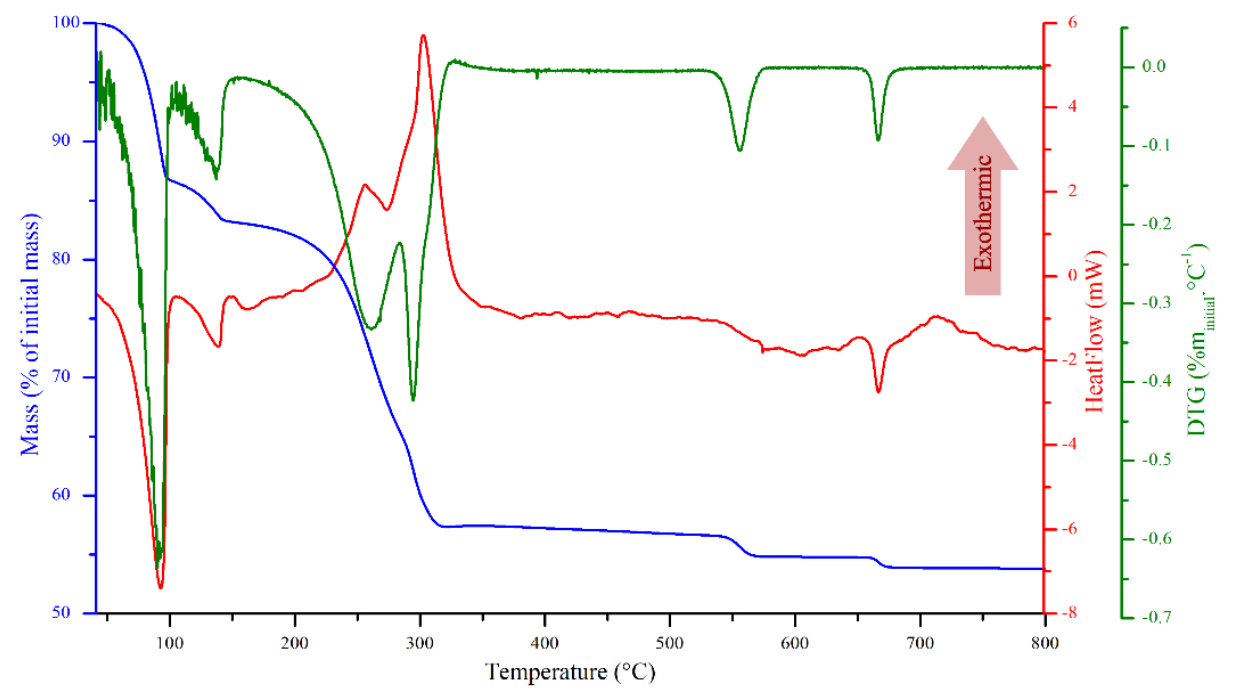

Figure 5. TG/DSC analysis performed on $\mathrm{U}\left(\mathrm{C}_{2} \mathrm{O}_{4}\right)_{2} \cdot 6 \mathrm{H}_{2} \mathrm{O}$ (TGA in blue, DTG in green and heat flow in red) under $\mathrm{He} / \mathrm{O}_{2}(25 / 75)$ at $1^{\circ} \mathrm{C} \cdot \mathrm{min}^{-1}$. 
If the study of the TGA, DTG and DSC signals under oxidizing atmosphere clearly indicates the existence of reaction intermediates, the only use of the mass loss does not allow us to conclude on the chemical nature of these compounds. Thermal treatments under isothermal and isobaric conditions were then performed to stabilize them under controlled atmosphere and temperature (Figure 6). This method led to the synthesis of four reaction intermediates. Stabilization of uranium oxalate dihydrate and monohydrate was deliberately left out since these intermediates are already reported in the literature with a good agreement between the different authors ${ }^{25,35}$ and are not specific of the thermal behavior in oxidizing conditions. The powders synthesized were labeled from $X_{1}$ to $X_{4}$ in ascending order of temperatures $\left(T_{X 1}=130^{\circ} \mathrm{C}, T_{X 2}=200^{\circ} \mathrm{C}, T_{x 3}=350^{\circ} \mathrm{C}\right.$ and $\left.T_{X 4}=550^{\circ} \mathrm{C}\right)$. In order to ensure a complete stabilization, thermal treatments were extended from 24 hours to 100 hours in order to reach mass variations lower than the experimental uncertainty (i.e. $10 \mu \mathrm{g}$ ).
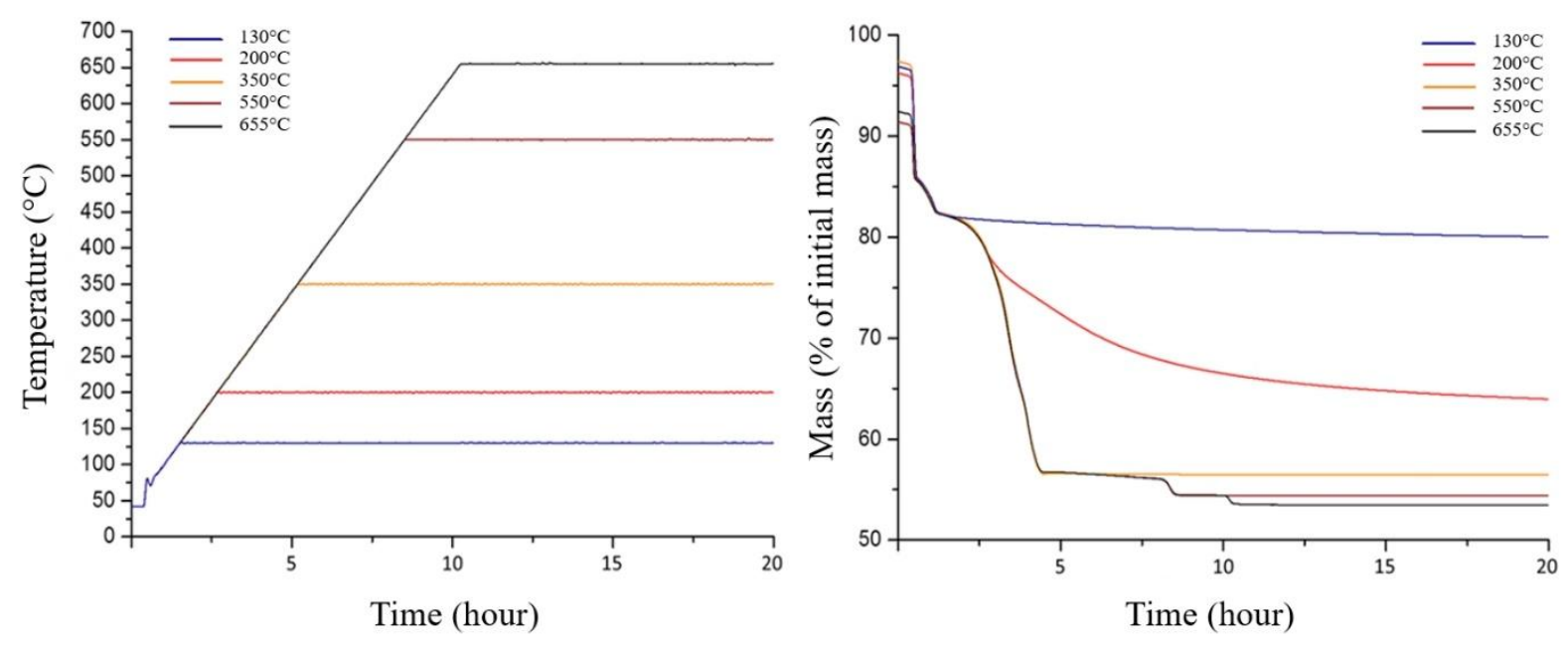

Figure 6. Temperature of the isothermal/isobaric experiments under $\mathrm{He} / \mathrm{O}_{2}(25 / 75)$ used to stabilize the reaction intermediates (left), and mass signals related to these experiments (right).

\section{III.3 Characterization of the reaction intermediates}

\section{III.3.1 PXRD}

First insights into the chemical nature of the reaction intermediates were first obtained through PXRD measurements and further pattern matching (Figure 7).

The product $\mathrm{X}_{1}$, formed after calcination at $130^{\circ} \mathrm{C}$, was found to be poorly crystallized, but still exhibits some characteristic diffraction lines of the anhydrous uranium(IV) oxalate described by Garela-Duvieubourg et al. ${ }^{27}$ (particularly the most intense reflections at $2 \theta=15$ and $20^{\circ}$ ).

In good agreement with the decomposition of the oxalate entities between 150 and $320^{\circ} \mathrm{C}, \mathrm{X}_{2}$ (stabilized at $200^{\circ} \mathrm{C}$ ) appeared to be amorphous. This observation comforts the hypothesis of a metastable compound formed during the heating ramp. Nevertheless, one can note that $X_{3}$ also presented a PXRD pattern characteristic of an amorphous sample. On this basis, heating at $350^{\circ} \mathrm{C}$ allowed to fully decompose the oxalate groups but was not sufficient to obtain a crystalline phase. 
Conversely, $\mathrm{X}_{4}$, which is the stable intermediate between 550 and $655^{\circ} \mathrm{C}$ is well crystallized and matches well with the $\alpha-\mathrm{UO}_{3}{ }^{43}$ pattern reported by Tsvigunov (orthorhombic $P$ with $a=13.882 \AA$, $b=43.021 \AA$ and $c=8.328 \AA$ ). Finally, and as it was expected from the data reported in the literature, the sample stabilized at the end of the heat treatment (i.e. for temperatures above $650^{\circ} \mathrm{C}$ ), corresponds to the hexagonal form of $\mathrm{U}_{3} \mathrm{O}_{8}$ (space group P-62m, $a=6.8210 \AA, c=4.1517 \AA$ ) ${ }^{44}$.

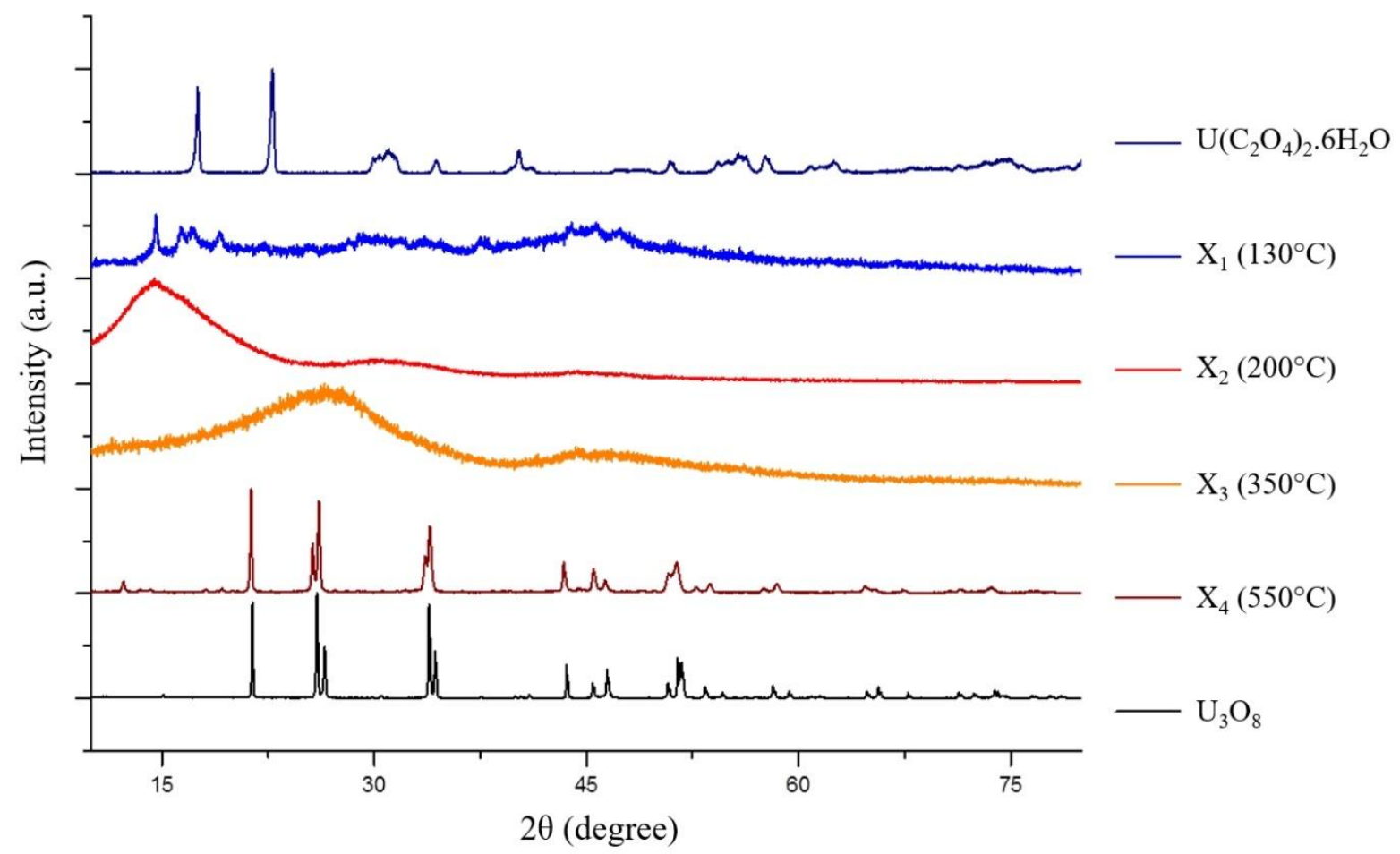

Figure 7. Powder XRD patterns recorded for $U\left(\mathrm{C}_{2} \mathrm{O}_{4}\right)_{2} \cdot 6 \mathrm{H}_{2} \mathrm{O}$, the four reaction intermediates and $\mathrm{U}_{3} \mathrm{O}_{8}$ obtained under oxidizing atmosphere.

\section{III.3.2 Vibrational spectroscopy}

The FTIR spectra for $\mathrm{U}\left(\mathrm{C}_{2} \mathrm{O}_{4}\right)_{2} \cdot 6 \mathrm{H}_{2} \mathrm{O}$, the four reaction intermediates and $\mathrm{U}_{3} \mathrm{O}_{8}$ are further gathered in Figure 8a. The $X_{1}$ and $X_{2}$ samples present the characteristic vibration bands of oxalates described previously for the precursor, especially at 1622 and $1310 \mathrm{~cm}^{-1}$. Additionally, the $X_{2}$ spectrum presents an intense signal around $930 \mathrm{~cm}^{-1}$, which could be assigned to the anti-symmetric stretching of the uranyl motif $\mathrm{v}_{3}\left(\mathrm{UO}_{2}\right)$. Indeed, similar feature was already observed for several other uranylcarboxylate compounds, such as uranyl acetate ${ }^{45}$. From this, it can be assumed that at this stage, uranium has at least partly oxidized to $\mathrm{U}(\mathrm{VI})$. 
a)

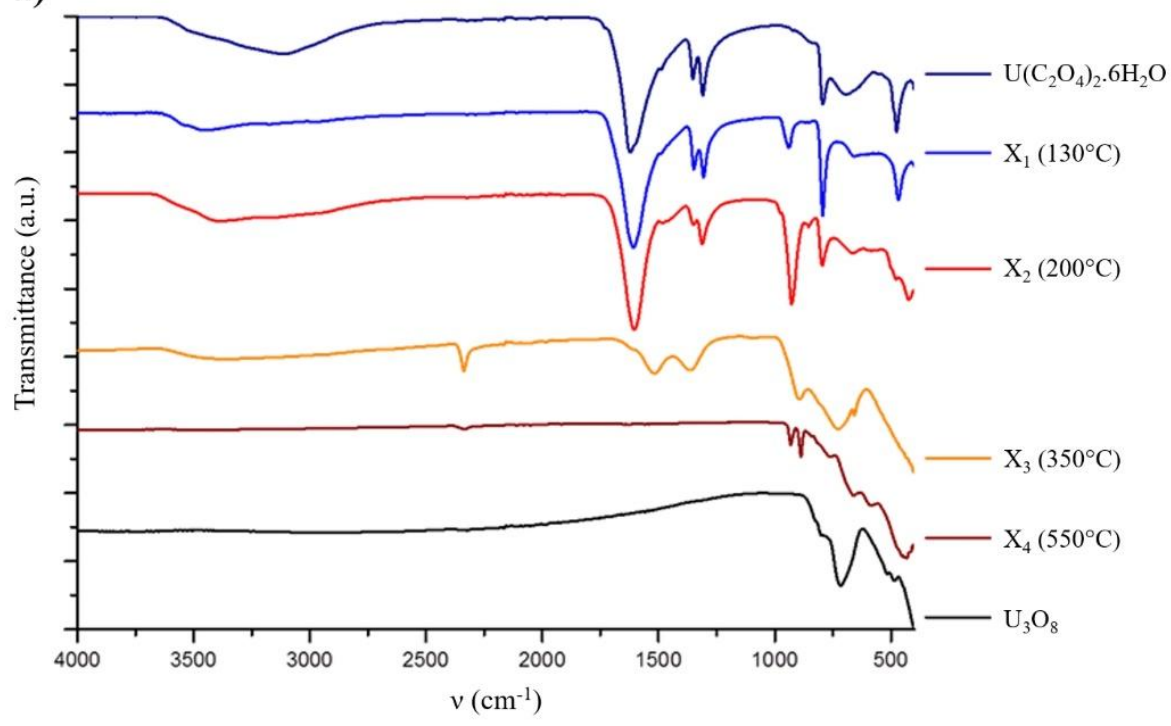

b)

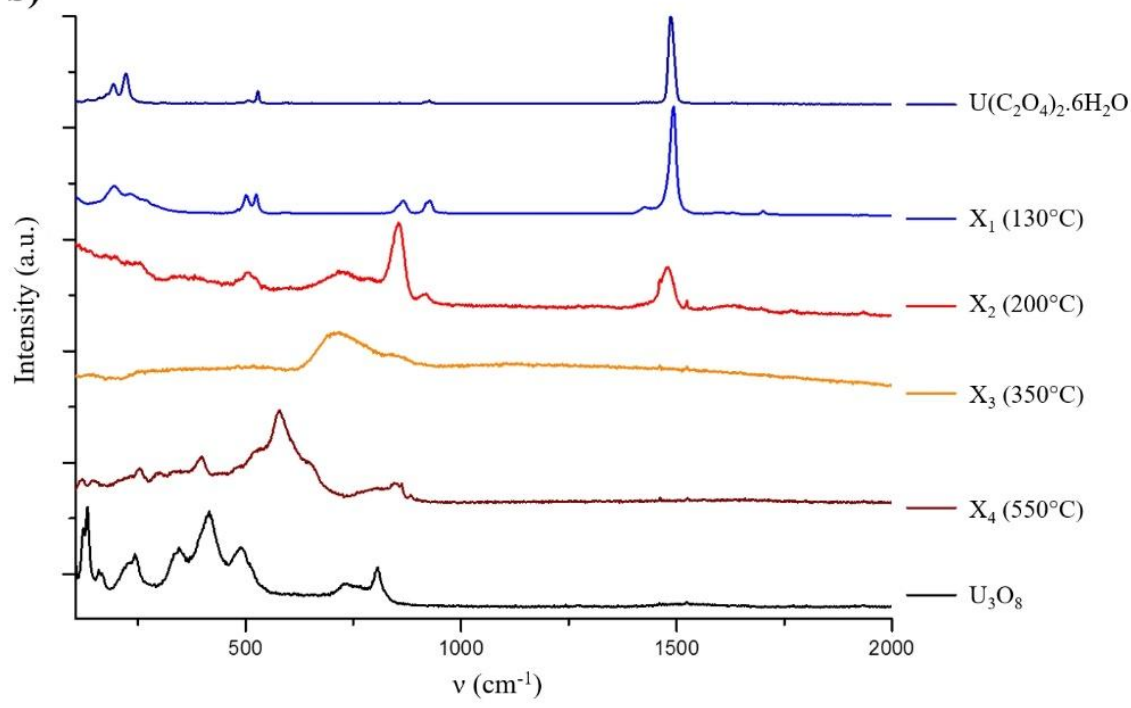

Figure 8. FTIR (a) and Raman (b) spectra of $\mathrm{U}\left(\mathrm{C}_{2} \mathrm{O}_{4}\right)_{2} \cdot 6 \mathrm{H}_{2} \mathrm{O}$, the four reaction intermediates and $\mathrm{U}_{3} \mathrm{O}_{8}$ obtained under oxidizing atmosphere.

The $X_{3}$ spectrum further evidenced deep modification in the structure of the samples, as the vibration bands assigned to oxalate groups vanished and were replaced by the characteristic vibration modes of carbonate groups ${ }^{[20]}$. Indeed, the bands at $1518 \mathrm{~cm}^{-1}$ and $1364 \mathrm{~cm}^{-1}$ could be assigned to the antisymmetric vibration of $\mathrm{CO}$ bonds, while the band at $1094 \mathrm{~cm}^{-1}$ represents the vibration $\mathrm{v}_{1}\left(\mathrm{CO}_{3}\right)$, the band at $893 \mathrm{~cm}^{-1}$ stems from the $\pi\left(\mathrm{CO}_{3}\right)$ vibration and the band at $725 \mathrm{~cm}^{-1}$ originates from the $\mathrm{v}_{4}\left(\mathrm{CO}_{3}\right)$ vibration. Also, one should note that the band at $2341 \mathrm{~cm}^{-1}$, associated to the $\mathrm{v}_{3}\left(\mathrm{CO}_{2}\right)$ vibration, was already reported during the conversion of $\mathrm{Pu}(\mathrm{IV})$ oxalate and assigned to the occlusion or the sorption of $\mathrm{CO}_{2}$ onto the solid phase ${ }^{5}$. Several authors also mentioned this signal but failed to provide any explanation ${ }^{46-48}$. 
Finally, the spectrum recorded for the $\mathrm{X}_{4}$ intermediate did not present any vibration band related to carbon-based species. This observation then shows that a heat treatment at $550^{\circ} \mathrm{C}$ is required if one wants to fully eliminate carbon residues within the final oxide powder. Also, the spectrum evidenced two bands at $930 \mathrm{~cm}^{-1}$ and $887 \mathrm{~cm}^{-1}$ which were already observed by Hoekstra, and ascribed to the hypo-stoichiometric $\mathrm{UO}_{2.9}$ oxide ${ }^{49}$.

In complement, Raman spectra (Figure 8b) confirmed the results obtained from FTIR and XRD. Nonetheless, it can be noted that the $X_{3}$ spectrum, which does not present any contribution except from a broad band around $700 \mathrm{~cm}^{-1}$, seems to concur with the amorphous compound described by Thomas et al. ${ }^{50}$ in their study of the thermal decomposition of uranium peroxide. Whether in this study or in Thomas', this compound decomposes into $\alpha-\mathrm{UO}_{3}$ as temperature increases.

\section{III.3.3 Chemical analysis}

With the aim to get further insight on the chemical composition of the reaction intermediates stabilized during the thermal conversion of $\mathrm{U}\left(\mathrm{C}_{2} \mathrm{O}_{4}\right)_{2} \cdot 6 \mathrm{H}_{2} \mathrm{O}$ under oxidizing atmosphere, and to quantify the organic-related species pointed out by vibrational spectroscopy, the mass ratio of carbon was measured in all the samples prepared (Table 1). In good agreement with XRD analyses, the data obtained for the $\mathrm{X}_{1}$ intermediate fits with the formation of the anhydrous form of uranium(IV) oxalate $(w t . \%(C)=11.8 \%)$. The lower value measured herein could be ascribed to the rehydration of the sample towards mono- or even dihydrate forms when brought back to ambient conditions. The $X_{2}$ intermediate was then found to present a carbon mass ratio divided by two compared to $X_{1}$, which agrees well with the TG analyses reported above. Also, this value remains very high and fully compatible with the presence of oxalate groups in the sample.

Conversely, the carbon mass ratio measured for products prepared after heating above $200^{\circ} \mathrm{C}$ was typically found below $1 \mathrm{wt} . \%$, which attests for the loss of a major part of the initial organic fraction. As such, the $\mathrm{X}_{3}$ intermediate cannot be assigned to the $\mathrm{UO}_{1.5}\left(\mathrm{CO}_{3}\right)_{0.5}$ product previously reported in the literature by Cilgi et al. ${ }^{24}$, which presents a theoretical carbon mass ratio of $2.04 \mathrm{wt} . \%$. The carbonate signal recorded by Raman spectroscopy then most likely arose from $\mathrm{CO}_{2}$ adsorbed at the surface of the solid, or occluded in its porosity. This residual amount of carbon further gradually decreased when increasing the temperature, to reach values as low as $0.05 \mathrm{wt} . \%$ in the final $\mathrm{U}_{3} \mathrm{O}_{8}$ product obtained after heating at $1000^{\circ} \mathrm{C}$. This result is close to those determined for other actinide oxides produced by thermal or hydrothermal conversion of oxalate counterparts ${ }^{39,51-53}$, and in the order of magnitude of the ASTM C753 standard for C impurities in nuclear-grade uranium oxide powders ${ }^{54}$.

Table 1. Mass ratio of residual carbon in the reaction intermediates and final product prepared after heat treatment of $U\left(\mathrm{C}_{2} \mathrm{O}_{4}\right)_{2} \cdot 6 \mathrm{H}_{2} \mathrm{O}$ under oxidizing atmosphere.

\begin{tabular}{lcccccc}
\hline Temperature $\left({ }^{\circ} \mathrm{C}\right)$ & 130 & 200 & 350 & 550 & 655 & 1000 \\
\hline Sample & $\mathrm{X}_{1}$ & $\mathrm{X}_{2}$ & $\mathrm{X}_{3}$ & $\mathrm{X}_{4}$ & & $\mathrm{U}_{3} \mathrm{O}_{8}$ \\
$\mathrm{C}$ wt.\% & 9.94 & 4.36 & 0.91 & 0.17 & 0.10 & 0.05 \\
\hline
\end{tabular}


In order to evidence the redox behavior of uranium during the calcination of uranium(IV) oxalate under oxidizing atmosphere, all the samples investigated were analyzed through HERFD-XANES. Indeed, applying the high-energy resolution fluorescence detection technique to the near edge structure of the absorption spectra enables enough resolution to separate contributions of oxidation states IV, V and VI of uranium ${ }^{55}$.

Comparing our samples with the standard compounds (Figure 9a) allowed us to show the evolution of uranium oxidation state depending on reaction pathway, particularly thanks to the HERFD-XANES maxima positions plotted in Figure $9 \mathbf{b}$. The $X_{1}$ intermediate exhibited a single contribution with a maximum around $3725 \mathrm{eV}$, which is characteristic of a pure $U$ (IV) sample. Conversely, $X_{2}$ (in red in Figure 9) appeared to be partly oxidized as two contributions are observed: a first one at $3725 \mathrm{eV}$ corresponding to $\mathrm{U}(\mathrm{IV})$ and a second one very similar to uranyl $\mathrm{UO}_{2}{ }^{2+}$ with a peak centered at 3726.5 $\mathrm{eV}$ and a smaller feature at about $3729 \mathrm{eV} . \mathrm{X}_{2}$ is then composed of a mixture of $\mathrm{U}(\mathrm{IV})$ and $\mathrm{U}(\mathrm{VI})$, with a $\mathrm{U}(\mathrm{VI})$ predominant contribution. As such, it is the first intermediate where uranium gets oxidized, meaning that this oxidation occurs at relatively low temperature $\left(200^{\circ} \mathrm{C}\right)$, i.e. early during the thermal treatment, and before the formation of any carbonate intermediate. As $X_{3}$ is almost identical to the $\mathrm{U}(\mathrm{VI})$ uranyl $\mathrm{UO}_{2}{ }^{2+}$, it cannot be identified as an uranium(IV) carbonate or uranium(IV) oxo-carbonate as stated in the literature, and was found to only contain $\mathrm{U}(\mathrm{VI})$ from these results. The sample further underwent a partial reduction at high temperature. Indeed, at $550^{\circ} \mathrm{C}$, the $\mathrm{X}_{4}$ product presented characteristic signal of $\mathrm{U}(\mathrm{V}) / \mathrm{U}(\mathrm{VI})$ mixture. In this case, the spectrum can be fitted through the use of a linear combination of $\mathrm{U}_{3} \mathrm{O}_{8}$ and $\mathrm{UO}_{2}{ }^{2+}$ spectra which corroborates the assumption made from FTIR results of $\mathrm{X}_{4}$ being a sub-stoichiometric $\mathrm{UO}_{3}$ oxide (such as $\mathrm{UO}_{2.9}$ ). Finally, the last spectrum collected agreed well with the formation of $\mathrm{U}_{3} \mathrm{O}_{8}$ as a mixture of $\mathrm{U}(\mathrm{V})$ and $\mathrm{U}(\mathrm{VI})$ was still observed. Nevertheless, the signal assigned to $\mathrm{U}(\mathrm{V})$ was more intense in this case than in $\mathrm{X}_{4}$. 


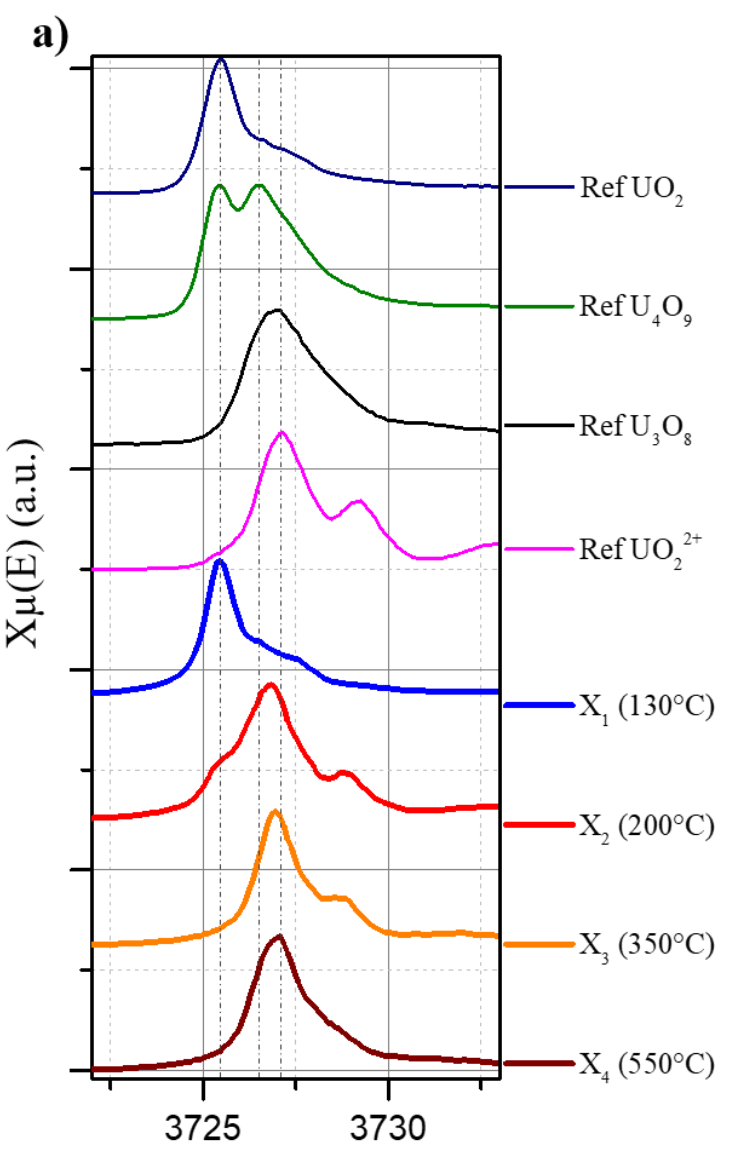

Energy (eV)

b)

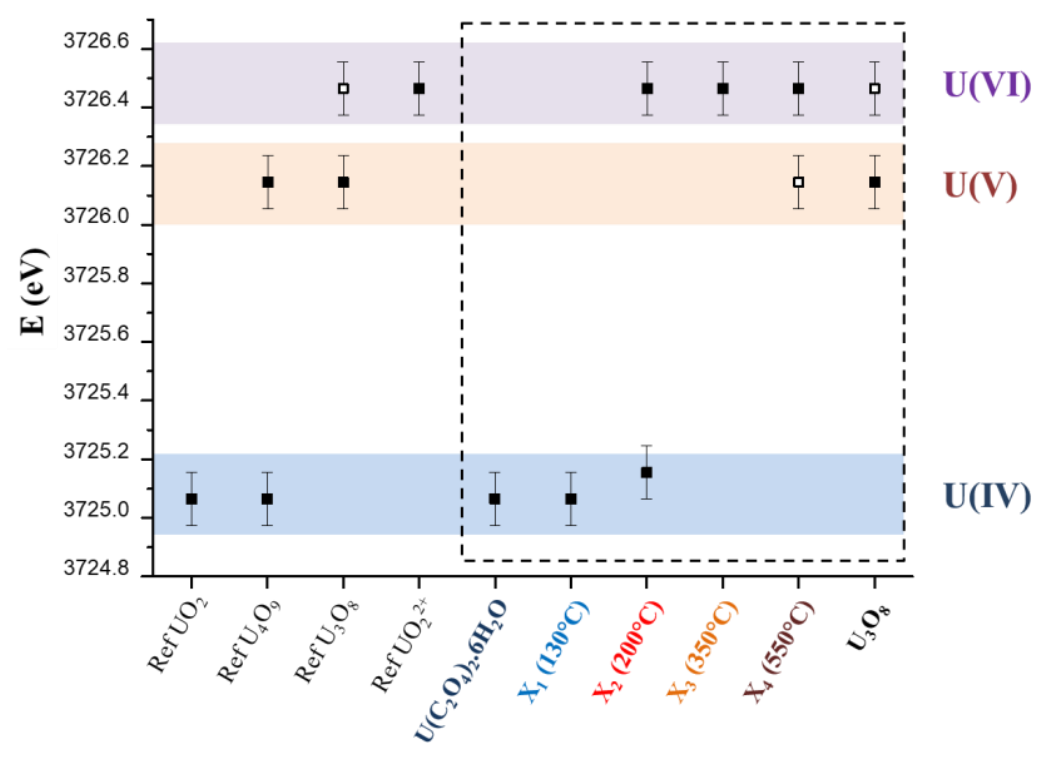

Figure 9. (a) $X \mu(E)$ of the four main reaction intermediates obtained under oxidizing atmosphere and standard compounds. (b) comparison of oxidation states between reference compounds (names in black) and reaction intermediates (in the dotted box) deduce from $d X \mu(E)$ maxima with filled square standing for the main contributions. 
By combining the information gathered through the different analyses (from TG/DSC to spectroscopies) several plausible hypotheses can be formulated:

$\mathrm{X}_{1}$ : the first reaction intermediate can be identified to anhydrous uranium(IV) oxalate, $U\left(\mathrm{C}_{2} \mathrm{O}_{4}\right)_{2}$. This compound is formed even under oxidizing atmosphere. Nevertheless, temperatures far below $170^{\circ} \mathrm{C}$ (which corresponds to the onset of oxalates decomposition) are needed to stabilize it, particularly in order to avoid any reaction with oxygen. This low temperature is then probably the reason for the very long settling time observed. The endothermic behavior of the third dehydration is likely to be hidden by the exothermic behavior of the reaction that follows. Even if it is possible to stabilize this compound in the thermobalance, the broad band on the FTIR standing for the vibration of $\mathrm{OH}$ bond in $\mathrm{H}_{2} \mathrm{O}$ shows that a rehydration occurs immediately when $\mathrm{X}_{1}$ is submitted to ambient air.

$\mathbf{X}_{2}$ : the $\mathrm{X}_{2}$ intermediate, which originates from the reaction of anhydrous uranium(IV) oxalate with oxygen, still presents high level of residual carbon due to remaining oxalate groups, despite the important mass loss. Indeed, $83.3 \%$ of the total mass loss occurred while forming $X_{2}$, meaning that six water molecules and three quarters of the oxalate groups had already left out the solid. Also, uranium(IV) partially oxidized to $\mathrm{U}(\mathrm{VI})$ during this reaction, which comes along a heavily exothermic behavior contributing to the overall heat flow measured. As of today, the hypothesis of an exothermic behavior under oxygen derives only from the heat flow produced by the oxidation of $\mathrm{CO}$ into $\mathrm{CO}_{2}$ and does not explain the discrepancies between the different actinides (IV) and lanthanide (IV) oxalates ${ }^{19}$, for which the thermal decompositions are described in a similar way (the same quantities of $\mathrm{CO}$ emitted are expected). Also, the existence of an oxidation reaction occurring early in the global conversion pathway explains the significant differences noticed by differential scanning calorimetry and thermogravimetric analyses between thermal treatment under helium or under oxygen. As it stands, the analyses did not allow us to formulate a hypothesis about exact formulation.

$\mathbf{X}_{3}$ : two main informations were obtained for this intermediate. Firstly, it does not contain any oxalate group but some carbonates were detected. Secondly, uranium is fully oxidized to U(VI) in this sample. The weight fraction of carbon was measured using the combustion technique by a carbon/sulfur analyzer of LECO, in order to get insight about the formulation of this intermediate. The mass value at this stage of the decomposition accounts for $56.5 \%$ of the initial mass with less than $1 \mathrm{wt} . \%$ of carbon : the intermediate produced then cannot be assigned to $\mathrm{UO}_{1.5}\left(\mathrm{CO}_{3}\right)_{0.5}$ as reported previously ${ }^{24}$, but most likely to an amorphous $\mathrm{UO}_{3}$ phase with residual carbonate groups trapped within the microstructure (i.e. at grain boundaries, for example) or adsorbed onto the surface.

$\mathbf{X}_{4}$ : given the results obtained through PXRD, $\mathrm{X}_{4}$ can be described as the first crystallized oxide phase produced by the thermal decomposition of $\mathrm{U}\left(\mathrm{C}_{2} \mathrm{O}_{4}\right)_{2} \cdot 6 \mathrm{H}_{2} \mathrm{O}$ under oxidizing atmosphere. It corresponds to $\mathrm{UO}_{2.9}$, a sub-stoichiometric form of $\mathrm{UO}_{3}$ which was already reported in the literature ${ }^{49}$. This variation of the $\mathrm{O} / \mathrm{M}$ ratio could explain the slight mass loss deviation between the theoretical mass of $\mathrm{UO}_{3}$ (which accounts for $54.8 \%$ of the initial oxalate precursor mass), and the mass loss leading to $\mathrm{X}_{4}$ (i.e. $54.4 \%$ of the initial mass). The last thermal decomposition, between $\mathrm{X}_{4}$ and $\mathrm{U}_{3} \mathrm{O}_{8}$, is then a thermal reduction occurring at $655^{\circ} \mathrm{C}$, endothermic, which is in very good agreement with the phase diagram of the U-O system ${ }^{56}$. 
Based on these conclusions, the full scheme describing the conversion of uranium(IV) oxalate hexahydrate into $\mathrm{U}_{3} \mathrm{O}_{8}$ under oxygen could be written as follows :

$$
\begin{array}{ll}
\mathrm{U}\left(\mathrm{C}_{2} \mathrm{O}_{4}\right)_{2} \cdot 6 \mathrm{H}_{2} \mathrm{O} \rightarrow \mathrm{U}\left(\mathrm{C}_{2} \mathrm{O}_{4}\right)_{2} \cdot 2 \mathrm{H}_{2} \mathrm{O}+4 \mathrm{H}_{2} \mathrm{O} & \\
\mathrm{U}\left(\mathrm{C}_{2} \mathrm{O}_{4}\right)_{2} \cdot 2 \mathrm{H}_{2} \mathrm{O} \rightarrow \mathrm{U}\left(\mathrm{C}_{2} \mathrm{O}_{4}\right)_{2} \cdot \mathrm{H}_{2} \mathrm{O}+\mathrm{H}_{2} \mathrm{O} & (6) \\
\mathrm{U}\left(\mathrm{C}_{2} \mathrm{O}_{4}\right)_{2} \cdot \mathrm{H}_{2} \mathrm{O} \rightarrow \mathrm{U}\left(\mathrm{C}_{2} \mathrm{O}_{4}\right)_{2}+\mathrm{H}_{2} \mathrm{O} & \left(7, \mathrm{X}_{1} \text { formation }\right) \\
\mathrm{U}\left(\mathrm{C}_{2} \mathrm{O}_{4}\right)_{2} \rightarrow \mathrm{X}_{2}+x \mathrm{CO}_{2}+\mathrm{y} \mathrm{CO} & \left(8, \mathrm{X}_{2} \text { formation }\right) \\
\mathrm{X}_{2} \rightarrow \mathrm{UO}_{3} \text { (amorphous), } \varepsilon \mathrm{CO}_{3}+\mathrm{x}^{\prime} \mathrm{CO}_{2}+\mathrm{y}^{\prime} \mathrm{CO} & \left(9, \mathrm{X}_{3} \text { formation }\right) \\
\mathrm{UO}_{3} \text { (amorphous), } \varepsilon \mathrm{CO}_{3} \rightarrow \mathrm{UO}_{2.9}+\varepsilon \mathrm{CO}_{2}+(\varepsilon / 2+0.05) \mathrm{O}_{2} & \left(10, \mathrm{X}_{4}\right. \text { formation) } \\
1 / 3 \mathrm{UO}_{2.9} \rightarrow \mathrm{U}_{3} \mathrm{O}_{8}+7 / 60 \mathrm{O}_{2} &
\end{array}
$$

\section{III.4 Impact of the chemical transformations on the powder morphology}

In order to stress out the impact of the reactions mentioned above on the microstructure of the powder sample, SEM observations were performed on several intermediates as well as on the final product (Figure 10). As expected from the literature, which reports for long the pseudomorph character of the oxalate to oxide conversion ${ }^{57}$, the general habit, i.e. square shaped platelets, was kept all along the heat treatment. Deep modifications still occur when heating, consequently to both dehydration, decomposition and oxidation reactions. The $\mathrm{X}_{2}$ intermediate, obtained after heating at $200^{\circ} \mathrm{C}$, exhibited an important porosity, as well as slight hairline cracks in the platelets' thickness. These features are due to the elimination of gaseous species (i.e. $\mathrm{H}_{2} \mathrm{O}, \mathrm{CO}_{2}$ and $\mathrm{CO}$ ) during the decomposition process, which was already proved to create mesopores with a size of about 3-4 nm 58. The presence of porosity was still noted at the surface of the $X_{3}$ and $X_{4}$ intermediates, but to a lesser extent. Indeed, it was probably eliminated partially during heat treatment as a consequence of crystallites growth within the square-shape aggregates. At higher temperature (i.e. above $655^{\circ} \mathrm{C}$ ), the formation of $\mathrm{U}_{3} \mathrm{O}_{8}$ was correlated to an important growth of the crystallites forming the platelets, which conferred them a spheroidal aspect. Although such growth step was already reported for other metallic oxalates (including lanthanides and actinides) ${ }^{58,59}$, it is probably enhanced when dealing with uranium. Indeed, oxidation of $U(I V)$ into $U(V) / U(V I)$ is generally correlated with an increase of the uranium diffusion coefficients, which could be 3 orders of magnitude higher in $\mathrm{U}_{3} \mathrm{O}_{8}$ compared with $\mathrm{UO}_{2}{ }^{60,61}$. Consequently, grain growth phenomena are strongly promoted. 


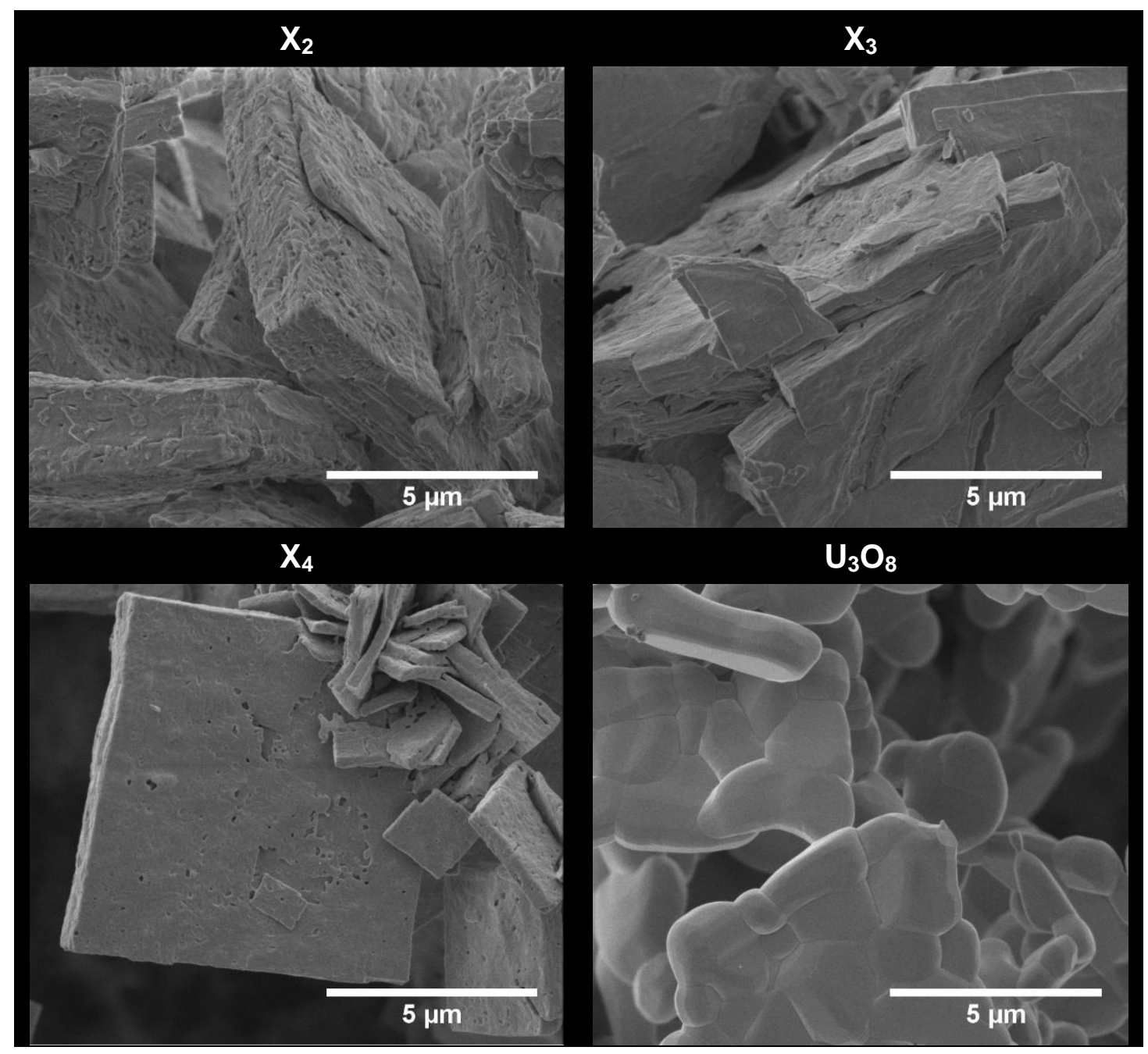

Figure 10. SEM image of $\mathrm{X}_{2}\left(200^{\circ} \mathrm{C}\right), \mathrm{X}_{3}\left(350^{\circ} \mathrm{C}\right), \mathrm{X}_{4}\left(550^{\circ} \mathrm{C}\right)$ and $\mathrm{U}_{3} \mathrm{O}_{8}\left(1000^{\circ} \mathrm{C}\right)$ obtained after thermal treatments under oxidizing atmosphere (24 hours).

Even if the global morphology of the square shaped platelets was not deeply modified during the heat treatment, their size is expected to be impacted by the important mass loss associated to the oxalate to oxide conversion. In order to monitor such a process, the variation of the surface of an aggregate was observed in situ during the heat treatment by the means of HT-ESEM (Figure 11). Hence, it is important to underline that experimental conditions here differed from previous heat treatments performed for TGA, both regarding the heating rate applied $\left(10^{\circ} \mathrm{C} \cdot \mathrm{min}^{-1}\right.$ vs $\left.1^{\circ} \mathrm{C} \cdot \mathrm{min}^{-1}\right)$ and the value of $\mathrm{pO}_{2}$ in the surrounding atmosphere (200 Pa vs $76 \mathrm{kPa}$ ). In spite of these modifications, the surface changes present a good correlation with the formation of the various reaction intermediates. However, fast heating rate precludes any quantitative exploitation of the results, and the shrinkage of the aggregate's surface can only be discussed qualitatively.

The dehydration of the initial precursor, leading to $U\left(\mathrm{C}_{2} \mathrm{O}_{4}\right)_{2}\left(\mathrm{X}_{1}\right)$, was found to produce a strong shrinkage, which can be linked to the decrease of the interlayer space hosting the water molecules in the 2D structure of An(IV) oxalates. Quite surprisingly, the important mass loss produced by the partial decomposition of the oxalate groups, which leads to the unknown intermediate $X_{2}$, produces a similar shrinkage between 130 and $200^{\circ} \mathrm{C}$. Conversely, while the transformation of $X_{2}$ to $X_{3}$ was 
correlated to only an additional $8 \%$ of mass loss, it was associated to the most important part of the shrinkage. At the end of this stage, the size of the sample was then reduced by $40 \%$ compared to the initial oxalate. As the samples formed above $350^{\circ} \mathrm{C}$ can be mostly identified to oxides, the size variation were further correlated to redox reactions. As such, the complete oxidation of uranium into $\mathrm{U}(\mathrm{VI})$ associated to the crystallization of $\mathrm{UO}_{2.9}$, led the powder to swell significantly. Conversely, the formation of $\mathrm{U}_{3} \mathrm{O}_{8}$ was not found to significantly affect the grain size, which is further only modified by the sintering operating at high temperature (i.e. above $900^{\circ} \mathrm{C}$ ).

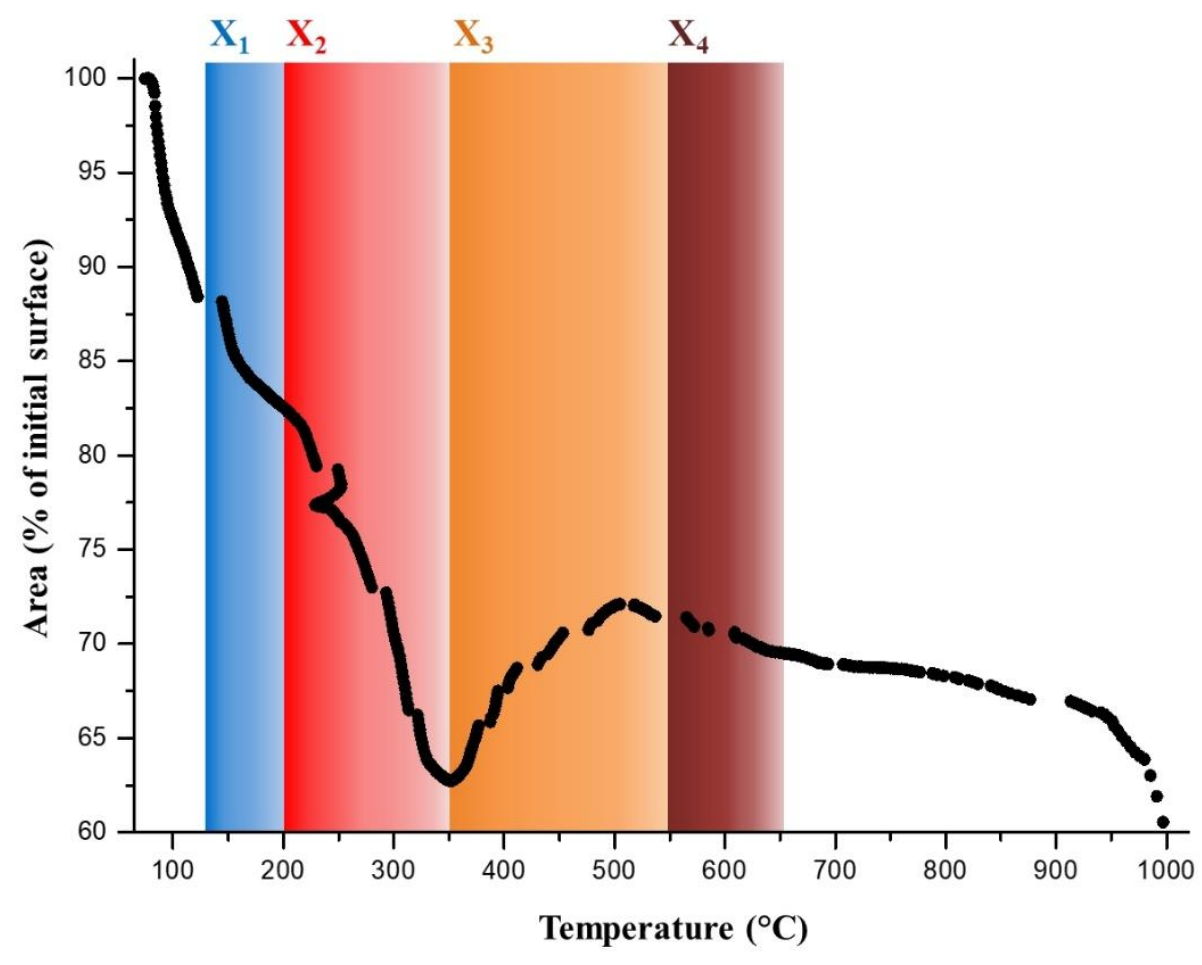

Figure 11. Relative variation of the surface of a square-shape aggregate monitored by HT-ESEM observations during the decomposition of $\mathrm{U}\left(\mathrm{C}_{2} \mathrm{O}_{4}\right)_{2} \cdot 6 \mathrm{H}_{2} \mathrm{O}$ under oxidizing atmosphere. The domain of existence of the various intermediates determined by TG analyses have been emphasized as an eye-guide.

\section{CONCLUSION}

The thermal decomposition of metal oxalates greatly depends on the oxidation state of the cation, the gas involved and the physical characteristics of the precursor. In the peculiar case of uranium(IV) oxalate, its sensibility towards oxidation leads to a specific series of reactions when heating under oxygen atmosphere. In this framework, the different intermediates formed were stabilized and characterized through a combination of various techniques (X-Ray diffraction, vibrational spectroscopy, X-Ray absorption near edge spectroscopy) in order to clarify the disagreements existing in the literature. Indeed, if the dehydration steps leading from the initial $U\left(\mathrm{C}_{2} \mathrm{O}_{4}\right)_{2} \cdot 6 \mathrm{H}_{2} \mathrm{O}$ to the anhydrous $\mathrm{U}(\mathrm{IV})$ oxalate $\mathrm{U}\left(\mathrm{C}_{2} \mathrm{O}_{4}\right)_{2}$ are subject to consensus, the exact decomposition path leading to the final $\mathrm{U}_{3} \mathrm{O}_{8}$ still remained uncertain, especially concerning the redox behavior of uranium. 
In this frame, this study showed for the first time that uranium oxidation proceeds at moderately low temperature (i.e. $200^{\circ} \mathrm{C}$ ), and is concomitant to the onset of the oxalate groups decomposition. As such, it could be, at least partly, responsible for the exothermic character of the U(IV) decomposition process. However, even if a reaction intermediate was stabilized at $200^{\circ} \mathrm{C}$, it remained difficult to assign it to an accurate formula, and it could be seen as an amorphous oxo-oxalato compound. Pursuing the thermal conversion up to $350^{\circ} \mathrm{C}$ led to complete oxidation of $\mathrm{U}(\mathrm{IV})$ into $\mathrm{U}(\mathrm{VI})$, then to the formation of an amorphous form $\mathrm{UO}_{3}$. This sample still bear a significant amount of carbon, probably present as carbonate entities adsorbed onto the surface of the powder or trapped into the mesopores resulting from the oxalate decomposition. The main part of this residual carbon is finally eliminated after firing at $550^{\circ} \mathrm{C}$, which also corresponds to the crystallization of sub-stoichiometric $\mathrm{UO}_{3-\delta}$, which then can be seen as the first pure oxide formed during the thermal conversion of $\mathrm{U}\left(\mathrm{C}_{2} \mathrm{O}_{4}\right)_{2} \cdot 6 \mathrm{H}_{2} \mathrm{O}$ under oxygen. Finally, in good agreement with the U-O binary diagram, $\mathrm{U}_{3} \mathrm{O}_{8}$ was obtained as the final stable phase after heating above $660^{\circ} \mathrm{C}$. This multistep thermal decomposition is summarized in Figure 12. This series of transformations was also found to significantly modify the granulometry of the powder through HT-ESEM observations. However, the global morphology of the square shaped platelets was not deeply modified during the heat treatment.

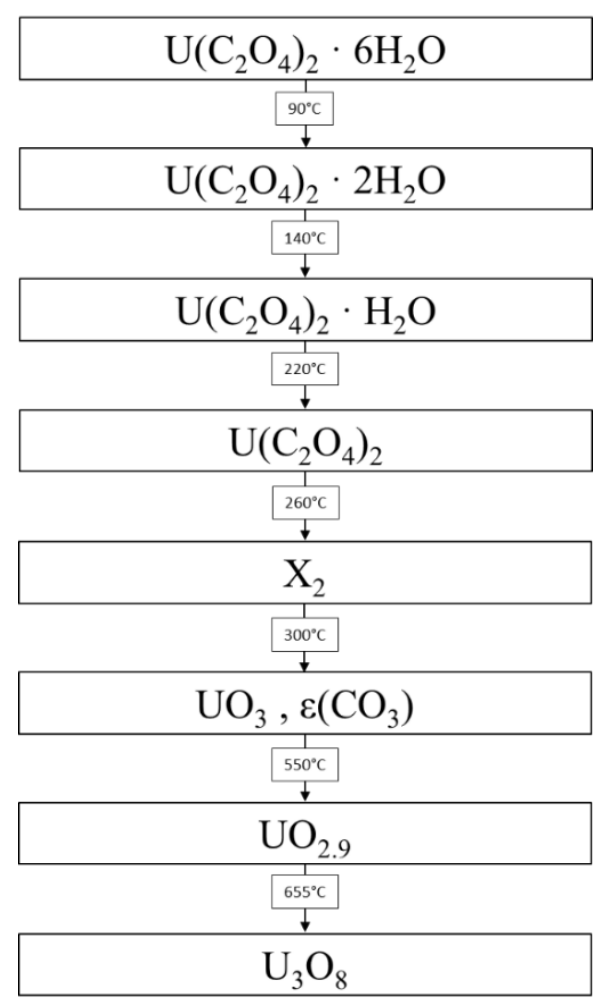

Figure 12. Summary of the multistep scheme evidenced in this work for uranium(IV) oxalate decomposition under oxidizing atmosphere.

The mechanism of thermal conversion of uranium(IV) oxalate into oxide under oxygen is then driven by a complex interplay between redox reactions and decomposition of the organic moieties. As both processes depends strongly on the experimental conditions used, it could easily explain the 
discrepancies observed up to now in the literature. It also shed a new light on the peculiar exothermic behavior already observed for this reaction.

In order to control final oxide characteristics, it appears fundamental to understand the mechanisms involved in each chemical reaction, and so to kinetically describe these reactions by means of surface nucleation and growth models developed for chemical transformations of solid phases. Since such kinetic models rely on the steady-state approximation and on the rate-determining step assumption, the experimental verification of both assumptions will be required for each reaction.

In a further work, these experimental validations as well as a kinetic model taking into account the present results and a detailed mechanism in elementary steps will be presented in the case of the thermal reduction of $\mathrm{UO}_{2.9}$ into $\mathrm{U}_{3} \mathrm{O}_{8}$.

\section{ACKNOWLEDGMENTS}

Authors would like to thank B. Corso (ICSM) for his support during PXRD experiments, as well as L. Vieille (Mines Saint-Etienne) for her help concerning TGA and TG-DSC experiments. We acknowledge SOLEIL for provision of synchrotron radiation facilities and beamtime.

\section{SUPPORTING INFORMATION}

XRD pattern of the starting uranium(IV) oxalate and in-situ HT-ESEM observation of its decomposition into $\mathrm{U}_{3} \mathrm{O}_{8}$. 


\section{REFERENCES}

1. Foo, Y. T.; Abdullah, A. Z.; Horri, B. A.; Salamatinia, B.: Optimised Co-Precipitation synthesis condition for oxalate-derived zirconia nanoparticles, Ceram Int 2019, 45, 22930-22939.

2. Majumdar, S.; Sharma, I. G.; Bidaye, A. C.; Suri, A. K.: A study on isothermal kinetics of thermal decomposition of cobalt oxalate to cobalt, Thermochim Acta 2008, 473, 45-49.

3. Silva, R. G.; Morais, C. A.; Oliveir, E. D.: Selective cerium removal by thermal treatment of mixed rare earth oxalates or carbonates obtained from non-purified rare earth sulphate liquor, Miner Eng 2019, 139, 105865.

4. Tyrpekl, V.; Markova, P.; Dopita, M.; Brazda, P.; Vacca, M. A.: Cerium Oxalate Morphotypes: Synthesis and Conversion into Nanocrystalline Oxide, Inorg Chem 2019, 58, 10111-10118.

5. Vigier, N.; Grandjean, S.; Arab-Chapelet, B.; Abraham, F.: Reaction mechanisms of the thermal conversion of $\mathrm{Pu}(\mathrm{IV})$ oxalate into plutonium oxide, J Alloy Compd 2007, 444, 594-597.

6. Horlait, D.; Lebreton, F.; Gauthe, A.; Caisso, M.; Arab-Chapelet, B.; Picart, S.; Delahaye, T.: Americium-based oxides: Dense pellet fabrication from co-converted oxalates, I Nucl Mater 2014, 444, 181-185.

7. Arab-Chapelet, B.; Grandjean, S.; Nowogrocki, G.; Abraham, F.: Synthesis and characterization of mixed An(IV)/An(III) oxalates (An(IV) = Th, Np, U or Pu and An(III) $=$ Pu or Am), $J$ Nucl Mater 2008, 373, 259-268.

8. Arora, C.; Sharma, A.; Soni, S.; Naik, Y.; Ramarao, G.: Solid-state reaction of strontium oxalate with uranium oxalate Application of TG, J Therm Anal Calorim 2016, 124, 43-49.

9. Arora, C.; Chejara, S.; Ramarao, G.; Naik, Y. P.: Application of thermogravimetric analysis in study of solid-state reaction between barium oxalate and uranyl oxalate, $J$ Therm Anal Calorim 2016, 124, 51-56.

10. De Almeida, L.; Grandjean, S.; Vigier, N.; Patisson, F.: Insights into the Thermal Decomposition of Lanthanide(III) and Actinide(III) Oxalates - from Neodymium and Cerium to Plutonium, Europ J Inorg Chem 2012, 4986-4999.

11. Sarsfield, M., The coprecipitation and conversion of mixed actinide oxalates for aqueous-based reprocessing of spent nuclear fuels. In Reprocessing and recycling of spent nuclear fuel, Taylor, R., Ed. Woodhead Publishing: Cambridge, UK, 2015; pp 325-351.

12. Boldyrev, V. V.: Thermal decomposition of silver oxalate, Thermochim Acta 2002, 388, 63-90.

13. Dollimore, D.: The Thermal-Decomposition of Oxalates - a Review, Thermochim Acta 1987, 117, 331-363.

14. Nusrath, K.; Muraleedharan, K.: Effect of nano-transition metal oxides of $\mathrm{Fe}, \mathrm{Co}$ and $\mathrm{Ni}$ and ferrites of $\mathrm{Co}$ and $\mathrm{Ni}$ on the multistage thermal decomposition of oxalates of $\mathrm{Ce}(\mathrm{III}), \mathrm{J}$ Therm Anal Calorim 2019, 136, 549-563.

15. Puzan, A. N.; Baumer, V. N.; Lisovytskiy, D. V.; Mateychenko, P. V.: Structure disordering and thermal decomposition of manganese oxalate dihydrate, $\mathrm{MnC}_{2} \mathrm{O}_{4} \cdot 2 \mathrm{H}_{2} \mathrm{O}$, J Solid State Chem 2018, 260, 87-94.

16. Sarada, K.; Vijisha, K. R.; Muraleedharan, K.: Exploration of the thermal decomposition of oxalates of copper and silver by experimental and computational methods, J Anal Appl Pyrol 2016, 120, 207-214.

17. Dollimore, D.: Influence of Environment on Thermal-Decomposition of Oxysalts, $J$ Therm Anal 1977, 11, 185-200.

18. Hourlier, D.: Thermal decomposition of calcium oxalate: beyond appearances, $J$ Therm Anal Calorim 2019, 136, 2221-2229.

19. Subramanian, M. S.; Singh, R. N.; Sharma, H. D.: Reaction Kinetics of Some Actinide Oxalates by Differential Thermal Analysis, J Inorg Nucl Chem 1969, 31, 3789-3795.

20. Chugh, C. A.; Sharma, A.; Sharma, A.; Shalu; Naik, Y. P.; Rao, G. A. R.: Kinetics and Mechanism of Thermal Decomposition of Uranyl Oxalate, Asian J Chem 2011, 23, 1865-1866. 
21. Cetisli, H.; Cilgi, G. K.; Donat, R.: Thermal and kinetic analysis of uranium salts Part 1. Uranium (VI) oxalate hydrates, J Therm Anal Calorim 2012, 108, 1213-1222.

22. Bharadwaj, D. S.; Murthy, A. R. V.: Studies on Thermal Behaviour of Uranium(IV) Oxalate, Indian J Chem 1964, 2, 391.

23. Bressat, R.; Claudel, B.; Trambouze, Y.: Etude de la Decomposition thermique des oxalates d'uranyle et d'uranium(IV), B Soc Chim Fr 1963, 464.

24. Cilgi, G. K.; Cetisli, H.; Donat, R.: Thermal and kinetic analysis of uranium salts, J Therm Anal Calorim 2014, 115, 2007-2020.

25. Duvieubourg-Garela, L.; Vigier, N.; Abraham, F.; Grandjean, S.: Adaptable coordination of U(IV) in the 2D- $(4,4)$ uranium oxalate network: From 8 to 10 coordinations in the uranium (IV) oxalate hydrates, J Solid State Chem 2008, 181, 1899-1908.

26. Wendlandt, W. W.; George, T. D.; Horton, G. R.: The Thermal Decomposition of Thorium(IV), Uranium(IV), and the Rare-Earth Metal(III) Oxalate Hydrates - Differential Thermal Analysis and Weight-Loss Studies, J Inorg Nucl Chem 1961, 17, 280-286.

27. Garela-Duvieubourg, L. Synthèse et structure de nouveaux oxalates ou squarates d'uranium(IV) et de lanthanide(III). Université de Lille, 2007.

28. Altas, Y.; Eral, M.; Tel, H.: Preparation of homogeneous $\left(\mathrm{Th}_{0.8} \mathrm{U}_{0.2}\right) \mathrm{O}_{2}$ powders by mechanical blending of $\mathrm{Th}\left(\mathrm{C}_{2} \mathrm{O}_{4}\right)_{2} .6 \mathrm{H}_{2} \mathrm{O}$ and $\mathrm{U}\left(\mathrm{C}_{2} \mathrm{O}_{4}\right)_{2} .6 \mathrm{H}_{2} \mathrm{O}$ powders, J Nucl Mater 2001, 294, 344-348.

29. Bertrand-Andrieu, M.; Plasari, E.; Baron, P.: Determination of nucleation and crystal growth kinetics in hostile environment - Application to the tetravalent uranium oxalate $\mathrm{U}\left(\mathrm{C}_{2} \mathrm{O}_{4}\right)_{2}$. $6 \mathrm{H}_{2} \mathrm{O}$, Can J Chem Eng 2004, 82, 930-938.

30. Schindelin, J.; Arganda-Carreras, I.; Frise, E.; Kaynig, V.; Longair, M.; Pietzsch, T.; Preibisch, S.; Rueden, C.; Saalfeld, S.; Schmid, B.; Tinevez, J. Y.; White, D. J.; Hartenstein, V.; Eliceiri, K.; Tomancak, P.; Cardona, A.: Fiji: an open-source platform for biological-image analysis, Nature Methods 2012, 9, 676-682.

31. Sitaud, B.; Solari, P. L.; Schlutig, S.; Llorens, I.; Hermange, H.: Characterization of radioactive materials using the MARS beamline at the synchrotron SOLEIL, J Nucl Mater 2012, 425, 238243.

32. Ravel, B.; Newville, M.: ATHENA, ARTEMIS, HEPHAESTUS: data analysis for X-ray absorption spectroscopy using IFEFFIT, I Synchrotron Radiat 2005, 12, 537-541.

33. Kvashnina, K. O.; Butorin, S. M.; Martin, P.; Glatzel, P.: Chemical State of Complex Uranium Oxides, Phys Rev Lett 2013, 111, 253002.

34. Desgranges, L.; Badinozzi, G.; Simeone, D.; Fischer, H. E.: Refinement of the $\alpha-\mathrm{U}_{4} \mathrm{O}_{9}$ Crystalline Structure: New Insight into the $\mathrm{U}_{4} \mathrm{O}_{9}->\mathrm{U}_{3} \mathrm{O}_{8}$ Transformation, Inorg Chem 2011, 50, 6146-6151.

35. Clavier, N.; Hingant, N.; Rivenet, M.; Dobbade, S.; Dacheux, N.; Barre, N.; Abraham, F.: X-ray diffraction and $u$-raman investigation of the monoclinic- orthorhombic phase transition in $\mathrm{Th}_{1 \text { - }}$ ${ }_{x} \mathrm{U}_{\mathrm{x}}\left(\mathrm{C}_{2} \mathrm{O}_{4}\right)_{2} \cdot 2 \mathrm{H}_{2} \mathrm{O}$ solid solutions, Inorg Chem 2010, 49, 1921-1931.

36. Nakamoto, K., Infrared and Raman spectra of inorganic and coordination compounds Application in coordination, organometallic, and bioinorganic chemistry. Wiley: Hoboken, New Jersey, 2009.

37. Horlait, D.; Claparede, L.; Tocino, F.; Clavier, N.; Ravaux, J.; Szenknect, S.; Podor, R.; Dacheux, $\mathrm{N}$.: Environmental SEM monitoring of $\mathrm{Ce}_{1-x} \mathrm{Ln}_{x} \mathrm{O}_{2-x / 2}$ mixed-oxide microstructural evolution during dissolution, J Mater Chem A 2014, 2, 5193-5203.

38. Lu, G.; Haes, A. J.; Forbes, T. Z.: Detection and identification of solids, surfaces, and solutions of uranium using vibrational spectroscopy, Coordin Chem Rev 2018, 374, 314-344.

39. Martinez, J.; Clavier, N.; Ducasse, T.; Mesbah, A.; Audubert, F.; Corso, B.; Vigier, N.; Dacheux, $\mathrm{N}$.: From uranium(IV) oxalate to sintered $\mathrm{UO}_{2}$ : Consequences of the powders' thermal history on the microstructure, J Eur Ceram Soc 2015, 35, 4535-4546.

40. Koga, N.; Suzuki, Y.; Tatsuoka, T.: Thermal Dehydration of Magnesium Acetate Tetrahydrate: Formation and in Situ Crystallization of Anhydrous Glass, J Phys Chem B 2012, 116, 1447714486. 
41. Perez-Maqueda, L. A.; Blanes, J. M.; Pascual, J.; Perez-Rodriguez, J. L.: The influence of sonication on the thermal behavior of muscovite and biotite, J Eur Ceram Soc 2004, 24, 27932801.

42. Gueneau, C.; Baichi, M.; Labroche, D.; Chatillon, C.; Sundman, B.: Thermodynamic assessment of the uranium-oxygen system, J Nucl Mater 2002, 304, 161-175.

43. Tsvigunov, A. N.; Kuznetsov, L. M.: On the type of $\alpha-\mathrm{UO}_{3}$ superstructure, Radiokhimiya 1979, 21, 747-753.

44. Desgranges, L.; Baldinozzi, G.; Rousseau, G.; Niepce, J. C.; Calvarin, G.: Neutron Diffraction Study of the in Situ Oxidation of $\mathrm{UO}_{2}$, Inorg Chem 2009, 48, 7585-7592.

45. Donova, I.; Stefov, V.; Aleksovska, S.: Synthesis, characterization and thermal decomposition of hydroxylammonium uranyl acetate, J Therm Anal Calorim 2000, 63, 125-132.

46. Nissen, D. A.: The Thermal-Decomposition of Plutonium(Iv) Oxalate Hexahydrate, J Therm Anal 1980, 18, 99-109.

47. Kozlova, R. D.; Karelin, A. I.; Lobas, O. P.; Matyukha, V. A.: Thermal-Decomposition of Neptunium(IV) Oxalate, Sov Radiochem+ 1984, 26, 292-296.

48. Balboul, B. A. A.; El-Roudi, A. M.; Samir, E.; Othman, A. G.: Non-isothermal studies of the decomposition course of lanthanum oxalate decahydrate, Thermochim Acta 2002, 387, 109114.

49. Hoekstra, H. R.; Siegel, S.: The Uranium-Oxygen System $-\mathrm{U}_{3} \mathrm{O}_{8}-\mathrm{UO}_{3}$, J Inorg Nucl Chem 1961, 18, 154-165.

50. Thomas, R.; Rivenet, M.; Berrier, E.; de Waele, I.; Arab, M.; Amaraggi, D.; Morel, B.; Abraham, F.: Thermal decomposition of $\left(\mathrm{UO}_{2}\right)_{2}\left(\mathrm{H}_{2} \mathrm{O}\right)_{2}$. $2 \mathrm{H}_{2} \mathrm{O}$ : Influence on structure, microstructure and hydrofluorination, J Nucl Mater 2017, 483, 149-157.

51. Balakrishna, P.; Varma, B. P.; Krishnan, T. S.; Mohan, T. R. R.; Ramakrishnan, P.: Thorium Oxide - Calcination, Compaction and Sintering, J Nucl Mater 1988, 160, 88-94.

52. Manaud, J.; Maynadie, J.; Mesbah, A.; Hunault, M. O. J. Y.; Martin, P. M.; Zunino, M.; Meyer, D.; Dacheux, N.; Clavier, N.: Hydrothermal Conversion of Uranium(IV) Oxalate into Oxides: A Comprehensive Study, Inorg Chem 2020, 59, 3260-3273.

53. White, G. D.; Bray, L. A.; Hart, P. E.: Optimization of Thorium Oxalate Precipitation Conditions Relative to Derived Oxide Sinterability, J Nucl Mater 1981, 96, 305-313.

54. ASTM, Standard Specification for Nuclear-Grade, Sinterable Uranium Dioxide Powder. In West Conshohocken, PA, 2016; Vol. ASTM C753-16a.

55. Leinders, G.; Bes, R.; Pakarinen, J.; Kvashnina, K.; Verwerft, M.: Evolution of the Uranium Chemical State in Mixed-Valence Oxides, Inorg Chem 2017, 56, 6784-6787.

56. Higgs, J. D.; Lewis, B. J.; Thompson, W. T.; He, Z.: A conceptual model for the fuel oxidation of defective fuel, J Nucl Mater 2007, 366, 99-128.

57. Horlait, D.; Clavier, N.; Dacheux, N.; Cavalier, R.; Podor, R.: Synthesis and characterization of $\mathrm{Th}_{1-\mathrm{x}} \mathrm{Ln}_{\mathrm{x}} \mathrm{O}_{2-\mathrm{x} / 2}$ mixed-oxides, Mater Res Bull 2012, 47, 4017-4025.

58. Claparede, L.; Clavier, N.; Dacheux, N.; Mesbah, A.; Martinez, J.; Szenknect, S.; Moisy, P.: Multiparametric Dissolution of Thorium-Cerium Dioxide Solid Solutions, Inorg Chem 2011, 50, $11702-11714$.

59. Claparede, L.; Clavier, N.; Dacheux, N.; Moisy, P.; Podor, R.; Ravaux, J.: Influence of Crystallization State and Microstructure on the Chemical Durability of Cerium-Neodymium Mixed Oxides, Inorg Chem 2011, 50, 9059-9072.

60. Matzke, $\mathrm{H} .:$ On Uranium Self-Diffusion in $\mathrm{UO}_{2}$ and $\mathrm{UO}_{2+x} J \mathrm{Nucl}$ Mater 1969, 30, 26-35.

61. Leme, D. G.; Matzke, $\mathrm{H} .:$ The Diffusion of Uranium in $\mathrm{U}_{3} \mathrm{O}_{8}$, J Nucl Mater 1983, 115, 350-353. 


\section{FOR TABLE OF CONTENTS ONLY}

To clarify the existing disagreements, reaction intermediates formed during the thermal conversion of $\mathrm{U}\left(\mathrm{C}_{2} \mathrm{O}_{4}\right)_{2} \cdot 6 \mathrm{H}_{2} \mathrm{O}$ into $\mathrm{U}_{3} \mathrm{O}_{8}$ were characterized through $\mathrm{XRD}$, vibrational spectroscopies and XANES. Uranium oxidation was observed at $200^{\circ} \mathrm{C}$ concomitantly to the onset of oxalate decomposition. Heating at $350^{\circ} \mathrm{C}$ led to complete oxidation of $\mathrm{U}(\mathrm{IV})$ into $\mathrm{U}(\mathrm{VI})$, then to the formation of amorphous $\mathrm{UO}_{3}$. This latter was destabilized to sub-stoichiometric $\mathrm{UO}_{3-\delta}$ at $550^{\circ} \mathrm{C}$, while $\mathrm{U}_{3} \mathrm{O}_{8}$ was obtained as the final stable phase above $660^{\circ} \mathrm{C}$.

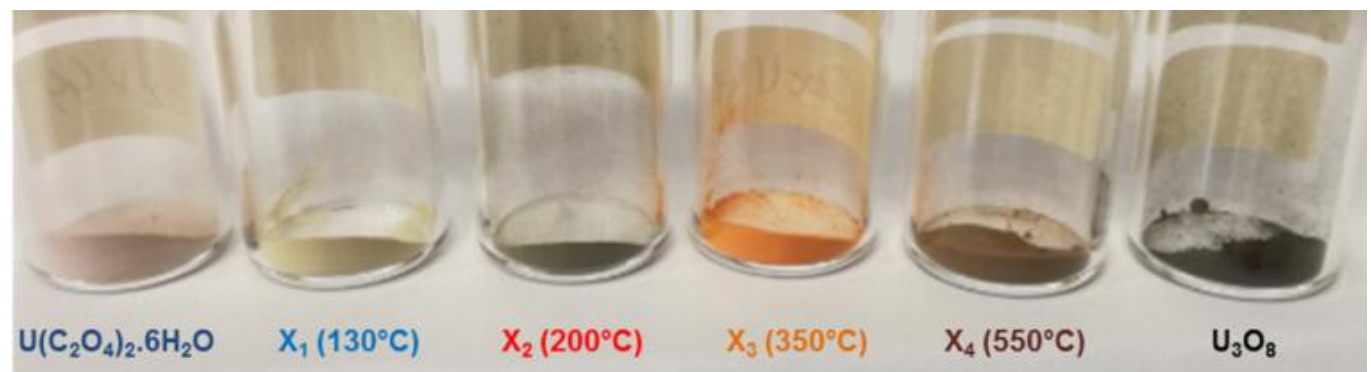

